\title{
COMPARING THE TRANSFORMATIVE POTENTIALS OF THE FCCC AND THE CCD: AN ECOFEMINIST EXPLORATION
}

\author{
Kate Wilkinson Cross *
}

\section{ABSTRACT}

Ecofeminists have long exposed the gendered character of human progress and its destructive impact on social and environmental commons. They contend that mainstream strategies responding to environmental crises reaffirm the subordination of women and non-human nature, while also reinforcing the power structures that sustain a white, heteronormative and masculine hegemony. While there is significant ecofeminist scholarship in gender and environment studies, there is little research to date which deconstructs international environmental law in order to explore the extent to which it maintains, reinforces or transforms understandings about human/non-human connections and their gendered nature. This article contributes to broader ecofeminist scholarship by synthesising Karen Warren's ecofeminist ethics into an analytical framework through which to analyse international environmental law. The article develops an original analysis of how transformational international legal regimes have been in shaping the international community's view of the environment and human/non-human interconnections. Comparing the often-ignored UN Convention to Combat Desertification (UNCCD) 1994, as well as the more (in)famous UN Framework Convention on Climate Change (UNFCCC) 1992, the author evaluates to what extent these regimes engage with and respond to the underlying institutional, structural, social, and conceptual frameworks that contribute to the continued degradation of the environment. The author concludes that while these regimes have transformative potential, they both continue to affirm an ideological perspective that disembeds humanity from the environment, while at the same time commodifying nature in order to protect it.

Keywords: UNFCCC, UNCCD, climate change, desertification, ecofeminism, ecofeminist ethics, international law,

\footnotetext{
* Lecturer in Law, Faculty of Business and Law, De Montfort University. My thanks to the anonymous reviewers for their critical reading of the manuscript and suggested improvements. Thank you also to colleagues at the Law School for their helpful comments on various drafts of this article. Email: kate.wilkinson@dmu.ac.uk
} 


\section{INTRODUCTION}

Desertification and climate change are intimately interrelated phenomena. With global temperatures rising because of climate change, there are higher incidences of drought, desertification and heatwaves. ${ }^{1}$ The combination of climate change and desertification has a disproportionate effect on communities already vulnerable and disadvantaged because of broader economic, social, cultural and political factors. For example, at the time of writing, communities in Mali, Malawi and Kenya are facing starvation due to drought and changes in rainfall. ${ }^{2}$ These examples show the very real impact of climate change, drought and desertification on the lives of people living in vulnerable communities.

Over the last thirty years, the international community has mobilised international legal and policy responses to desertification and climate change. The international community first discussed desertification in 1977 at the United Conference on Desertification, where it adopted the Plan of Action to Combat Desertification. ${ }^{3}$ Since then, concerns over the impact of desertification and drought have been raised in various fora, including the 1992 United Nations Conference on Environment and Development. ${ }^{4}$ After significant campaigning by developing countries, states adopted the 1994 United Nations Convention to Combat Desertification in those Countries Experiencing Serious Drought and/or Desertification, Particularly in Africa (UNCCD). This Convention outlines the obligations for states to undertake with respect to desertification and drought.

${ }^{1}$ Qi Feng and others, 'What Has Caused Desertification in China?' (2015) 5 Scientific Reports 15998.

2 ICRC, 'Community-Level Economic Support Provides a Lifeline for Women in Northern Mali' (2018) <https://www.icrc.org/en/document/mali-economicsecuritycommunity-support-lifeline-women $>$ accessed 28 February 2018; Charles Mkoka, 'Drought-Hit Malawi Farmers Use Sugar and Fish Soup to Battle Pests', Reuters (26 February 2018); Agatha Ngotho, 'Herders Get Sh175m to Ease Effects of Drought', The Star (Kenya, 28 February 2018) <https://www.thestar.co.ke/news/2018/02/28/herders-get-sh175m-to-ease-effects-ofdrought_c1721731> accessed 28 February 2018.

${ }^{3}$ United Nations, 'Plan of Action to Combat Desertification' (United Nations Conference on Environment and Development 1977) UN Doc A/CONF.74/36, (1977).

4 Agenda 21: Programme of Action for Sustainable Development 1992 (UN Conference on Sustainable Development) (14 June 1992) UN Doc A/Conf151/126/Rev1 vol I Chapter 12. 
Compared to the issue of desertification, climate change is a relative newcomer, being first characterised as a "common concern" for humankind by the UN General Assembly in 1988, and again in 1989. ${ }^{5}$ The General Assembly established an intergovernmental negotiating process under its auspices to negotiate a Framework Convention on Climate Change in $1990{ }^{6}$ Two years later, after tense negotiations, states adopted the 1992 United Nations Framework Convention on Climate Change (UNFCCC). As will be shown below, these regimes have very different origins, histories and positions on the international stage. However, both offer transformative potential to engage with the underlying institutional, structural, social, and conceptual frameworks that contribute to the continued degradation of the environment.

This article compares the "transformative potential" of the UNFCCC and UNCCD regimes. For the purposes of this article, "transformative" refers to how far these regimes engage with the underlying institutional, structural, social, and conceptual frameworks that contribute to the continued degradation of the environment. Where these regimes engage with and seek to alter these frameworks, they demonstrate transformative potential - even if such transformation has not

In order to explore the transformative potential of these two regimes, this article analyses and compares their legal texts through an ecofeminist analytical framework based on the boundary conditions of Karen Warren's ecofeminist ethics. ${ }^{7}$ Her ethics are particularly suited to exploring the transformative potentials of the UNFCCC and UNCCD regimes because they enable a nuanced analysis of the values, assumptions and beliefs informing the development of these two regimes. Because this ethical framework re-envisions political strategies, ethical frameworks and scientific understandings, it enables a comparison between the current positions, strategies and frameworks incorporated in these regimes against an explicitly transformative ethic.

As will be explained in section two of this article, the analytical framework developed in this article draws on three of Warren's boundary

\footnotetext{
${ }^{5}$ United Nations General Assembly Res 42/53 'Protection of the Climate for Present and Future Generations of Mankind' (6 December 1988) UN Doc A/RES/52/53 preamble; United Nations General Assembly Res 44/207 'Protection of the Global Environment for Present and Future Generations' (22 December 1989) UN Doc A/RES/44/207 preamble.

${ }^{6}$ United Nations General Assembly Res 45/212 'Protection of the Climate for Present and Future Generations’ (21 December 1990) UN Doc A/RES/45/212.

${ }^{7}$ See Karen J Warren, Ecofeminist Philosophy: A Western Perspective on What It Is and Why It Matters (Rowman \& Littlefield 2000).
} 
conditions to form interconnecting lenses through which the legal texts of the environmental regimes are read. ${ }^{8}$ The first and second lenses are labelled "inclusivity" and "contextuality". They have relevance when comparing the extent to which the participatory provisions of the climate change and desertification regimes are transformative in scope. They are also relevant when comparing the types of knowledge that are valued within each regime. The third and final lens is called "structural pluralism". This lens illuminates how sameness and difference are approached within the two regimes. Because of the transformative nature of Warren's ecofeminist ethics, they enable a nuanced comparison the UNFCCC and UNCCD regimes.

This article begins by introducing the UNFCCC, UNCCD, and the concept of sustainable development which informs both agreements. Section two outlines the key points of ecofeminist theory and sets out the analytical framework developed from Warren's ecofeminist ethics. Section three analyses the two agreements and their policy documents to compare and contrast the transformative potential embedded in their texts. Using the three lenses - inclusivity, contextuality and structural pluralism - it compares the ways in which they treat the voices of marginalised communities and ecosystem services, their approaches to integrating science and technology into the environmental regimes, and the operationalism of the principle of common but differentiated responsibilities as a way to attend to and recognise differences in capacities between states. Section four summarises the analysis and reflects on the extent to which these regimes fulfil their transformative potential.

\subsection{Introducing sustainable development, the UNCCD and UNFCCC}

The UNCCD and UNFCCC focus on the issues of desertification and climate change respectively. Both refer to the importance of attaining sustainable development. While not a new concept, ${ }^{9}$ sustainable

\footnotetext{
${ }^{8}$ This article builds on previous research developed in Kate Wilkinson Cross, 'The Environment as Commodity? An Ecofeminist Analysis of the Extent to Which Associations between Security and the Environment Have Altered the Perception of the Environment in International Law' (PhD thesis, University of Sheffield 2016); Kate Wilkinson Cross, 'Ecofeminist Potentials for International Environmental Law' in Douglas A Vakoch and Sam Mickey (eds), Ecofeminism in Dialogue (Lexington Books 2017).

9 See Marie-Claire Cordonier Segger and Ashfaq Khalfan, Sustainable Development Law: Principles, Practices, and Prospects (Oxford University Press
} 
development has emerged over the last forty years or so as "an important concept in global efforts to balance economic, social and environmental policies and laws." ${ }^{10}$ Because of its importance to the evolution of the two regimes, this article will first introduce sustainable development, its key principles and why the international community have latched onto it as an agenda to achieve poverty eradication, economic growth and environmental preservation. ${ }^{11}$

\subsubsection{Sustainable development in international law and policy}

The most accepted definition of sustainable development is "development that meets the needs of the present without compromising the ability of future generations to meet their own needs". ${ }^{12}$ Thus, there are two key elements to this concept. First, the substantive recognition that development should meet human needs by seeking to end poverty. Second, the concept recognises that there are limits to development: it must be "bounded by the evolving constraints of human abilities (technology, governance), and also by diverse environmental limitations." 13 Therefore, sustainable development can be understood as a "bridge" which recognises that the obligation towards future generations requires a balance between economic and social development pressures and environmental limits.

Sustainable development is constructed to "frame cooperative, integrative solutions to some of the most significant challenges of our era" that change over time. ${ }^{14}$ Therefore, it can be understood as an "integrationist principle" whose "components seek to balance the competing economic, social and environmental interests of the

2004) 15-23; Philippe Sands and others, Principles of International Environmental Law (4th edn, Cambridge University Press 2018) 217-21.

${ }^{10}$ Cordonier Segger and Khalfan (n 9) 15.

${ }^{11}$ United Nations General Assembly Res 70/1 'Transforming our world: the 2030 Agenda for Sustainable Development' (25 September 2015) UN Doc A/RES/70/1 para 5 .

12 WCED, Our Common Future (World Commission on Environment and Development; Oxford University Press 1987) 8.

${ }^{13}$ Cordonier Segger and Khalfan (n 9) 3.

14 Ibid. 
international community". ${ }^{15}$ It is explicitly human-centred ${ }^{16}$ and this is reflected in both the substantive and procedural elements of the concept.

Some of the key procedural elements of sustainable development require states, non-state actors and other participants to empower, consult, support public participation, undertake impact and risk assessments, and expand capacity-building and other undefined opportunities. These principles have been included in international law and policy relating to the environment. ${ }^{17}$ The breadth and depth of law and policy indicates that the procedural elements of sustainable development have been widely accepted by the international community. ${ }^{18}$ The substantive elements of sustainable development place limitations on the exploitation of the natural environment and are articulated in principles such as inter-generational equity, differential treatment and the precautionary approach. ${ }^{19}$ These principles have also been included in international law and governance. ${ }^{20}$ However, compared to the procedural elements of sustainable development, their legal content remains underdeveloped. ${ }^{21}$

${ }^{15}$ Wilkinson Cross, 'The Environment as Commodity?' (n 8) 44.

${ }^{16}$ Rio Declaration on Environment and Development 1992 (UN Conference on Environment and Development) (14 June 1992) UN Doc A/CONF151/26 (vol I); 31 ILM 874 (1992) principle 1.

${ }^{17}$ Convention (No 169) concerning Indigenous and Tribal Peoples in Independent Countries 1989 (adopted 27 June 1989, entered into force 5 September 1991) 28 ILM 1382 (1989); Rio Declaration 1992; Protocol on Access to Genetic Resources and the Fair and Equitable Sharing of Benefits Arising from their Utilisation to the Convention on Biological Diversity (adopted 29 October 2010, entered into force 12 October 2014) UNEP/CBD/COP/DEC/X/1 (29 October 2010); Pulp Mills on the River Uruguay (Argentina v Uruguay) Judgement, 2010 ICJ Reports 14; Certain Activities Carried Out by Nicaragua in the Border Area (Costa Rica v Nicaragua) Provisional Measures, Order of 8 March 2011, 2011 ICJ Reports 6; The South China Sea Arbitration (the Republic of the Philippines $v$ the People's Republic of China) Award, (12 July 2016) PCA Case No 2013-19.

${ }^{18}$ See in general, Sands and others (n 10) 197-250; Pierre-Marie Dupuy and Jorge E Viñuales, International Environmental Law (Cambridge University Press 2018) 58-99.

19 Philippe Sands, Principles of International Environmental Law (2nd edn, Cambridge University Press 2003) 253.

20 Stockholm Declaration on the Human Environment 1972 (United Nations Conference on the Human Environment) (16 June 1972) UN Doc A/CONF48/14/REV1 (1973); 11 ILM 1416 (1972) (1972); Rio Declaration 1992; Convention on Biological Diversity 1992 (CBD) (adopted 5 June 1992, entered into force 29 December 1993) 1760 UNTS 79; 31 ILM 818 (1992).

${ }^{21}$ For general discussion, see Dupuy and Viñuales (n 18); Sands and others (n 10). 
Sustainable development is an inherently flexible concept because it is both a process and a goal. It is a process that remains central to ongoing negotiations in environmental regimes and in the wider international community. It continues to evolve and remains central to collective and cooperative responses of the international community to the interrelated issues of sustainability and development.

\subsubsection{The UNCCD and its annexes}

As stated above, there have been long-term concerns over desertification. The 1977 Plan of Action to Combat Desertification was one of the first attempts to address the issue at the international level. However, by 1991, the UN Environment Programme concluded that international efforts had not been successful, and desertification had intensified. ${ }^{22}$ In light of these concerns, developing countries raised the issue of adopting a convention to combat desertification during the preparations for the 1992 Rio Conference on Environment and Development. ${ }^{23}$ Faced with significant opposition by countries within the Organisation for Economic Co-operation and Development (OECD), the finalised text of Agenda 21, which set out the international action plan to achieve sustainable development, included a paragraph outlining that an inter-governmental negotiating committee should be established for the elaboration of a convention to combat desertification. ${ }^{24}$ After difficult negotiations, states adopted the UNCCD in 1994 which entered into force in 1996.

The Convention is explicitly embedded in the paradigm of sustainable development. It adopts a bottom-up, holistic approach to preventing desertification at the local, national, and regional levels. It bases many of its objectives on attaining sustainable development, while also establishing differing obligations for developed country parties and affected developing country parties. ${ }^{25}$ By doing so, the Convention takes into account the social and economic development needs of developing countries while also addressing the serious environmental problem of desertification.

${ }^{22}$ UNEP, 'Status of Desertification and Implementation of the United Nations Plan of Action to Combat Desertification: Report of the Executive Director' (United Nations Environment Programme 1991) UN Doc UNEP/GC/SS.III/3.

${ }^{23}$ Bo Kjellen, 'The Saga of the Convention to Combat Desertification: The Rio/Johannesburg Process and the Global Responsibility for the Drylands' (2003) 12 RECIEL 127, 128.

${ }^{24}$ Agenda 211992 chapter 12.40.

${ }^{25}$ Pamela S Chasek, 'The Convention to Combat Desertification: Lessons Learned for Sustainable Development' (1997) 6 JED 147, 148. 
This integrative approach is embedded in the objectives of the UNCCD and in the ways in which parties should implement their obligations. Article 2 states that the objective of the UNCCD is to "combat desertification and mitigate the effects of drought in countries experiencing serious drought and/or desertification, particularly in Africa". ${ }^{26}$ Parties achieve this objective by ensuring effective action at all levels, within a framework of an "integrated approach", with a view to contributing towards achieving sustainable development in affected areas. Therefore, the UNCCD encourages parties to focus on improving the productivity of land, rehabilitating, conserving and sustainably managing land and water resources, which will lead to improved living conditions at the community level. ${ }^{27}$

\subsubsection{The UNFCCC regime}

The UNFCCC is a package of compromises. ${ }^{28}$ It contains elements for almost all the negotiating states, but no state was satisfied by the adopted convention. ${ }^{29}$ Therefore, at the time, many commentators viewed the UNFCCC as "punctuation mark in an ongoing process of negotiations." 30 The objective of the Convention is to stabilise greenhouse gas emissions at a level that prevents dangerous "anthropogenic interference with the climate system". ${ }^{31}$ It includes general principles to guide the parties' efforts in achieving stabilisation of the climate, including the precautionary approach, inter-generational equity, common but differentiated responsibilities, and sustainable development, among others. ${ }^{32}$

\footnotetext{
${ }^{26}$ United Nations Convention to Combat Desertification in those Countries Experiencing Serious Drought and/or Desertification, Particularly in Africa (adopted 17 June 1994, entered into force 26 December 1996) 1954 UNTS 3 art 2(1).

${ }^{27}$ Ibid art 2.

${ }^{28}$ Sands and others (n 9) 299.

${ }^{29}$ For a detailed history on the FCCC negotiations and entry into force, see Daniel Bodansky and others, International Climate Change Law (Oxford University Press 2017) 102-05.

${ }^{30}$ Ibid 105.

${ }^{31}$ United Nations Framework Convention on Climate Change 1992 (adopted 9 May 1992, entered into force 21 March 1994) 1771 UNTS 107 art 2.

32 Ibid art 3.
} 
The climate change regime has subsequently evolved through the adoption of two other legally binding agreements, ${ }^{33}$ as well as subsequent Conference of the Parties (COP) decisions. Recognising that the commitments included in the UNFCCC were unlikely to reduce greenhouse gas emissions, the parties adopted the Kyoto Protocol in 1997. This Protocol contains additional commitments for developed countries to limit their anthropogenic emissions through targets. ${ }^{34}$ Like the UNFCCC, the Protocol and subsequent COP decisions reflect a consolidation of a "topdown" regime in which states set internationally-defined, legally-binding emission reduction targets, in line with the guiding principles of the UNFCCC. ${ }^{35}$ This top-down approach has been subject to criticisms in terms of both of effectiveness and in terms of the differentiation between developed and developing countries within the regime. ${ }^{36}$

In 2015, the international community adopted the Paris Agreement, which came into force in 2016. Unlike the previous two agreements, the Agreement addresses the long-term commitments by all parties, rather than maintaining the traditional firewall between developed and developing countries. Rather than including an annex of targets and timetables, the Paris Agreement introduces the concept of "nationally determined contributions" (NDCs) as a bottom-up approach towards mitigating climate change. ${ }^{37}$ This bottom-up approach means that parties to the Agreement submit their own contributions towards addressing climate change, based on their individual national circumstances. Thus, there are no top-down, internationally agreed targets and timetables and instead, the aim is to ensure that each party achieves their commitments and does not fall back

\footnotetext{
${ }^{33}$ Kyoto Protocol to the United Nations Framework on Climate Change 1997 (adopted 11 December 1997, entered into force 16 February 2005) 2303 UNTS 162; Paris Agreement 2015 (signed 12 December 2015, entered into force 4 November 2016) FCCC/CP/2015/10/Add1.

${ }^{34}$ Kyoto Protocol art 3.

${ }^{35}$ William Hare and others, 'The Architecture of the Global Climate Regime: A Top-Down Perspective' (2010) 10 Climate Policy 600, 601-02; Daniel Bodansky, 'A Tale of Two Architectures: The Once and Future UN Climate Change Regime' (Arizona State University Sandra Day O'Connor College of Law, 7 March 2011) 2.

${ }^{36}$ Steve Rayner, 'How to Eat an Elephant: A Bottom-Up Approach to Climate Policy’ (2010) 10 Climate Policy 615.

${ }^{37}$ Paris Agreement art 3.
} 
on them. ${ }^{38}$ As yet, how this will work is still to be negotiated through the meeting of the Parties to the Paris Agreement (known as the CMA). ${ }^{39}$

This short overview highlights that both regimes have faced controversy during their initial creation and in their subsequent evolution. They share some similarities in terms of the content and references to broader economic and development factors. They both include references to the paradigm of sustainable development. Both recognise that external issues, such as international trade, economic development, social development, levels of technical capacity and other factors, affect the extent to which different communities will be able to achieve the objectives and obligations under each agreement. They each have transformative potential fundamentally to address the environmental problems faced by communities around the globe.

However, unlike the UNCCD, the climate change regime is never out of the spotlight. The issues of differentiation, the tension between developed and developing countries, the gendered aspect of climate change, and the relationship between climate change mitigation, adaptation, and sustainable development all mean that the regime remains in focus. The UNCCD on the other hand, has produced an evaluation of the effectiveness of its communication due to concerns that it was reaching a limited audience and that its message was getting lost. ${ }^{40}$ This demonstrates institutional concern that environmental problems such as desertification and drought are being subsumed by the continued focus on climate change. Not only does this limit the pressure exerted by civil society on their states to fulfil their obligations under the UNCCD, but it also means that the UNCCD has less academic and scholarly interest invested in it. Therefore, any transformative potential that it has may be underexplored and insufficiently highlighted. This article addresses this relative lack of interest by comparing and exploring the transformative potentials of these two regimes through an ecofeminist analytical framework, introduced below.

\footnotetext{
${ }^{38}$ Ibid art 4; Decision 1/CP21 'Adoption of the Paris Agreement' (12 December 2015) FCCC/CP/2015/10/Add1 paras 205, 23-25.

39 FCCC, 'Progress Tracker: Work Programme Resulting from the Relevant Requests Contained in Decision 1/CP.21' (UNFCCC, 2018) $<$ http://unfccc.int/files/paris_agreement/application/pdf/pa_progress_tracker_200 617.pdf $>$ accessed 2 February 2018 (as of 19/01/2018).

40 UNCCD, 'Independent Evaluation of the Effectiveness of the UNCCD Communication' (UNCCD, 2015) 6-7

$<$ https://www.unccd.int/sites/default/files/relevant-links/2017-

01/Communication $\% 20$ evaluation $\% 20$ report $\% 20$ formatted $\% 20$ final.pdf $>$ accessed 5 February 2018.
} 


\section{ECOFEMINISM AND ITS RELEVANCE TO INTERNATIONAL LAW}

Unlike other approaches to the study of the environment, ecofeminism make the connection between the exploitation of the environment and the subordination of women central in its analysis. ${ }^{41}$ In the mainstream, ecofeminism is usually presented as essentialist and uncritical, claiming that women are closer to nature than men. ${ }^{42}$ This does a disservice to the scholarship which incorporated materialist and posthumanist analysis of gender and the environment prior to these being popular within mainstream Western academia. ${ }^{43}$ It developed highly critical accounts of rationalist science, capitalism, speciesism, colonialism, racism, and sexism (hetero and queer), which are central to ecological feminist scholarship. ${ }^{44}$ These accounts incorporate Marxist, socialist, socioeconomic, historical, epistemological, and political perspectives. ${ }^{45}$ Therefore, ecofeminism has evolved into a philosophy, social activism and an intellectual commitment which questions the theoretical and ideological basis of the maledomination of women and non-human nature.

${ }^{41}$ Greta Claire Gaard, 'Living Interconnections with Animals and Nature' in Greta Claire Gaard (ed), Ecofeminism: Women, Animals, Nature (Temple University Press 1993) 1.

${ }^{42}$ See e.g. Andrew Dobson, Green Political Thought (3rd edn, Routledge 2000); John S Dryzek, The Politics of the Earth: Environmental Discourses (3rd edn, OUP Oxford 2013).

${ }^{43}$ Sherilyn MacGregor, 'Gender and Environment: An Introduction' in Sherilyn MacGregor (ed), Routledge Handbook of Gender and Environment (Taylor \& Francis 2017) 1.

${ }^{44}$ For a broad overview of ecofeminist theory and its evolution, see e.g. Charis Thompson and Sherilyn MacGregor, 'The Death of Nature: Foundations of Ecological Feminist Thought' in Sherilyn MacGregor (ed), Routledge Handbook of Gender and Environment (Taylor \& Francis 2017); Noël Sturgeon, Ecofeminist Natures: Race, Gender, Feminist Theory, and Political Action (Routledge 1997); Val Plumwood, Feminism and the Mastery of Nature (Opening Out: Feminism for Today, Routledge 1993) 1-40; Mary Mellor, Feminism \& Ecology (Polity Press 1997); see also, AE Kings, 'Intersectionality and the Changing Face of Ecofeminism' (2017) 22 Ethics \& the Environment 63; Catriona MortimerSandilands and Bruce Erickson, Queer Ecologies: Sex, Nature, Politics, Desire (Indiana University Press 2010).

${ }^{45}$ Karen J Warren, 'Feminist Environmental Philosophy' in Edward N Zalta (ed), Stanford Encyclopaedia of Philosophy (Summer 2015, Metaphysics Research Lab, Stanford University 2015). 
This breadth and depth of analysis directly challenges the mainstream typology of ecofeminism as limited, simplistic and essentialist. For example, John Dryzek's key text on environmental discourses frames ecofeminism as "cultural" and "spiritual". ${ }^{46}$ Andrew Dobson similarly introduces ecofeminist scholarship as primarily interested in explaining the cultural and social potential of privileging "female" characteristics such as empathy and care in his book on green political thought. ${ }^{47}$ Both authors pay limited attention to more recent scholarship, which draws on feminist science studies, feminist political economy, feminist political ecology, as well as feminist normative theory that "promotes and enacts ethical commitments to inclusivity, intersectionality, and democracy" 48 while also demanding an end to the exploitation of non-human nature and the "the dismantling of power structures that sustain, white, masculine, heteronormative hegemony within human societies." ${ }^{49}$ Therefore, these books provide an unrepresentative account of ecofeminist academic work by focusing on the essentialist works of early ecofeminist literature even though this work reflects an evolutionary dead-end in the development of ecofeminist theory.

As introduced above, ecofeminists critique the exploitative and gendered conceptual frameworks that underpin the dominant and rational discourses in western society. These are formed by a set of values, attitudes, beliefs, and assumptions that shape and mirror how an entity views itself and the world around it, and a number of different factors such as class, religion, nationality, gender, and race/ethnicity can alter the mirror in which an entity views itself. ${ }^{50}$ As such, ecofeminism provides a "spotlight" on some of the "shared conceptual roots of the unjustified dominations of women, non-human animals, and nature". ${ }^{51}$

This critique is used by many ecofeminists to explore the interconnecting ways in which these shared conceptual roots function in real life to maintain institutions and practices of oppression and domination. ${ }^{52}$ It can also question the practical implications for this

\footnotetext{
${ }^{46}$ Dryzek (n 42) 190-91.

${ }^{47}$ Dobson (n 42).

${ }^{48}$ MacGregor (n 43) 8.

49 Ibid.

${ }^{50}$ Plumwood, Feminism and the Mastery of Nature (n 44).

${ }^{51}$ Warren, 'Feminist Environmental Philosophy' (n 45).

52 E.g. Chris J Cuomo, Toward Thoughtful Ecofeminist Activism (Ecological Feminist Philosophies, Indiana University Press 1996); Kate Darling, 'A Weight for Water: An Ecological Feminist Critique of Emerging Norms and Trends in
} 
continued domination in social systems and institutions, including the global market economy, international environmental institutions, and through the implementation of international environmental law (IEL) and policy at the local level. ${ }^{53}$ Karen Warren articulates an ecofeminist theory that is "transformative" because it seeks to transform feminism and environmentalism, and guide broader social change. ${ }^{54}$ Her theory does two things: it gives an analysis of oppressive conceptual frameworks and how they reinforce interconnected institutions and practices. It also re-envisions the political strategies, theoretical positions, ethical frameworks, scientific understandings, and methodological approaches to develop peaceful and healthy social systems, communities, and people. ${ }^{55}$ These two aspects of her philosophy make it a sound basis from which to compare and critically evaluate international law relating to desertification and climate change.

\subsection{Introducing Karen Warren's boundary conditions}

Warren's vision of ecofeminist ethics is based on eight key boundary conditions. These are conditions "within which ethical decision-making may be seen as feminist." ${ }^{16}$ As discussed in previous work, there are certain conditions that are particularly relevant to the analysis of IEL. ${ }^{57}$ These are outlined below before turning to explain how these conditions may be integrated into an analytical framework.

Warren states that an ecofeminist ethic must be "anti-sexist, anti-racist, anti-classist, anti-naturist [sic], and opposed to any "ism" that presupposes

Global Water Governance' (2012) 13 Melb J Int'1 L 1; Greta Gaard, 'Ecofeminism and Climate Change' (2015) 49 Women's Stud Int Forum 20.

${ }^{53}$ Kate Wilkinson, 'Payment for Ecosystem Services and the Green Economy: Green Washing or Something New?' (2014) 5 JHRE 168; Kate Wilkinson, 'Is this the Future We Want? An Ecofeminist Comment on the UN Conference on Sustainable Development Outcome Document' in Kim Rubenstein and Katherine G Young (eds), The Public Law of Gender: From the Local to the Global (Cambridge University Press 2016); Wilkinson Cross, 'Ecofeminist Potentials' (n 8).

${ }^{54}$ Karen J Warren, 'Response to My Critics' (2002) 7 Ethics \& the Environment $39,41$.

${ }^{55}$ Ibid 42.

${ }^{56}$ Gaard (n 41) 2.

57 Wilkinson, 'Payment for Ecosystem Services' (n 53); Wilkinson Cross, 'The Environment as Commodity?' (n 8); Wilkinson Cross, 'Ecofeminist Potentials' (n 9). 
or advances a logic of domination"58. It must be contextual and see ethical "discourse and practice as emerging from the "voices" of entities located in different historical circumstances" ${ }^{59}$ Therefore, it is a "kind of narrative about humans, human-human relationships and human-non-human animal or nature relationships". ${ }^{60}$ It places as centrally significant "how a moral agent is in relationship to another - and not simply the nature of the agent or 'other', or the rights, duties, and the rules that apply to the agent or "other"". 61

Her ecofeminist ethics are inclusivist. This means that it emerges from and reflects the diversity of perspectives of marginalised peoples and women. ${ }^{62}$ As ecofeminism opposes the nature/culture dualism, it acknowledges that humans are members of an ecological community, but also different from other members. Therefore, ecofeminist ethics can recognise differences and commonalities between humans and non-human nature.

Warren's ethics "[provide] a central place for values typically unnoticed, underplayed, or misrepresented in traditional ethics". ${ }^{63}$ Examples of such values include friendship, love or care. Her ethics emphasise that evaluating or deciding whether such values are useful or appropriate in any given discussion will depend on the context. For example, when discussing contracts or property relationships, then the talk of rights can be useful and appropriate. When deciding what is advantageous and cost-effective for most people, speaking about utility can be appropriate.

Building on the above, ecofeminist ethics are "structurally plural" because they reject the assumption that there is one unified voice through which ethical values, beliefs, attitudes and conduct can be assessed. ${ }^{64}$ Therefore, they presuppose and maintain difference, both between humans as well as between humans and some elements of non-human nature. ${ }^{65}$ This means that her ethics affirm that humans are members of an ecological community (in some respects) while also being different from it. An important aspect for the analysis of international law is that Warren's ethics

\footnotetext{
${ }^{58}$ Warren, Ecofeminist Philosophy (n 7) 99.

${ }^{59}$ Ibid.

${ }^{60}$ Ibid.

61 Ibid.

62 Ibid 99-100.

${ }^{63}$ Ibid 100.

${ }^{64}$ Ibid 139.

65 Ibid 142.
} 
pay attention to relationships and community, and the respectful acknowledgement of them.

Finally, Warren's ethics reject "gender-free or gender-neutral descriptions of humans, ethics and ethical decision-making". ${ }^{66}$ This means that they reject "abstract individualism" which is the position "that it is possible to identify a human essence or human nature that exists independently of any particular historical context". ${ }^{67}$ Therefore, her ethics recognise that relationships "play an essential role in shaping what it is to be human" and that relationships between humans and non-human nature are a constitutive aspect of what it is to be human. ${ }^{68}$

Ecofeminist ethics are "care-sensitive ethics". According to Warren, "care-sensitive ethics" have three features that must be met before ethical principles in Western philosophy can qualify as a "bona fide ethical position". ${ }^{69}$ First, a central aspect of moral reasoning and motivation is the ability to care about others as well as oneself. Second, and building on the above features of an ecofeminist ethic, the universality of the ethical principles should be situated rather than ahistorical, transcendent and universal. Third, the appropriateness of the ethical principle in a given context is determined by the considerations of care. Therefore, traditional values such as utility, duty, and rights can be morally salient, so long as the application of the principle satisfies the three conditions of a care-sensitive ethic.

As argued elsewhere, this aspect of her ecofeminist ethics is important for the analysis of IEL. ${ }^{70}$ This is because it provides the foundation to undertake a highly contextualised and nuanced analysis of the underlying assumptions and ethical principles that have informed the development of the two legal regimes.

\subsection{Introducing the ecofeminist analytical framework}

The first lens - inclusivity - incorporates the boundary conditions that seek to include entities traditionally excluded or "othered" by Western philosophy. The second lens - contextuality - draws out a central theme within the boundary conditions that focuses on historical context and how this informs social relations. It explores how the two regimes pay attention

\footnotetext{
66 Ibid 101.

${ }^{67}$ Ibid.

${ }^{68}$ Ibid 143.

${ }^{69}$ Ibid 101.

${ }^{70}$ Wilkinson Cross, 'The Environment as Commodity?' (n 8) 108-14; Wilkinson Cross, 'Ecofeminist Potentials' (n 8) 209-10.
} 
to history and context. It examines how certain values which are underplayed by traditional ethics are incorporated within the legal regimes. It pays particular attention to the context in which discussions of different ethical principles, such as utility and rights are raised, and if they emerge from voices located in different historical circumstances. Finally, it explores the extent to which the legal documents reject abstract individualism by recognising the historical context that plays a central role in shaping humanity, and shaping the norms and law created during that time. $^{71}$

The third lens - structural pluralism - explores how these regimes pay attention to and respect plurality between entities, states, and values. This theme is reflected in the boundary conditions that presuppose and maintain difference between humans, and between humans and non-human nature. It affirms that humans are members of an ecological community, and of different human, social communities. ${ }^{72}$ In the context of IEL, it enables a nuanced analysis of the ways in which the international community seeks to balance the different interests that relate to the environment in this area of law. ${ }^{73}$ In this analysis, I will be able to consider what this might mean about the diversity of views of the environment at the international level. Finally, it draws on criticisms by some writers and activists that there should be a "bottom-up" approach to the creation and implementation of IEL that accounts for diversity, location, and difference. ${ }^{74}$

These three lenses, taken together, form an interconnecting framework through which to compare the transformative potential of the two international environmental regimes. Each has stronger synergies with differing aspects of international law-making and governance. For example, the inclusivity lens has stronger synergies in relation to the participation by different communities in the creation of international law and the subsequent implementation of obligations. Contextuality is relevant when exploring which issues are prioritised during the negotiations, and which other global regimes remain unaffected or distinct from the legal obligations within different environmental regimes. Structural pluralism focuses on how the regimes attend to differences between parties and other actors within the regime. As these lenses are interconnected and

${ }^{71}$ Wilkinson Cross (n 53).

${ }^{72}$ Niamh Moore, 'Eco/Feminism and Rewriting the End of Feminism: From the Chipko Movement to Clayoquot Sound' (2011) 12 Fem Theory 3, 11.

${ }^{73}$ Wilkinson Cross (n 8) 111; Wilkinson Cross (n 8) 210.

${ }^{74}$ Vandana Shiva, Staying Alive: Women, Ecology and Development (Zed 1988); Dharam Ghai and Jessica M Vivian, Grassroots Environmental Action: People's Participation in Sustainable Development (Routledge 1992); Sturgeon (n 44) 14166; Maria Mies and others, Ecofeminism (Zed Books 2014). 
intersecting, they enable a recognition that different categories, such as participation, the inclusion of other international interests, and the way in which the environment is represented, bleed into each other, have their own intersections, and cannot be analysed independently from each other.

\section{COMPARING THE UNFCCC AND THE UNCCD}

This section compares the legal and policy documents of the UNFCCC and UNCCD through the analytical framework introduced above. Focusing on the principles, norms and obligations incorporated into the two regimes, the analysis suggests that the treatment of women, the environment, and the incorporation of science and technology within these two regimes simply reaffirms and extends the dominant conceptual frameworks informing the evolution of IEL. This ultimately inhibits the transformative potential contained in these two regimes because it limits the space for engaging in open and participative conversations about humanity, history, ethics and our position within broader ecological systems.

\subsection{Comparing the participation of marginalised communities and ecosystem services in the UNFCCC and UNCCD through the inclusivity lens}

The following section explores the transformative potentials of the two regimes by comparing two elements important to ecofeminist ethics: the participation by state and non-state actors in the creation and subsequent evolution of the two legal regimes; and how the two regimes approach material embodiment of humanity within an ecological community. It is argued that the failure to integrate a gender dimension into the regime until relatively recently, and the historically limited reference to inclusive participation in the creation and implementation of objectives within the climate regime each highlight the ways in which the regime does not eradicate the "isms" of domination or fully incorporate the voices of marginalised communities. The introduction of ecosystem services as a key element of both regimes suggests that they treat the ecosystem as a commodity. This in turn reinforces the separation between human and nonhuman nature, thus legitimising the exploitation and commodification of non-human nature.

\subsubsection{Marginalised communities' participation in the two regimes: comparing the transformative potential}


The inclusion of traditionally marginalised communities during the creation of international agreements is a way in which states can seek to mitigate the "isms" of domination within the legal agreement. This is because it enables the voices of individuals who directly experience the impact of environmental degradation to be heard. Therefore, it can go in some way to identify how the assumptions informing different policies can detrimentally affect the lives of vulnerable communities by speaking truth to the ways in which broader social and economic structures maintain structural inequalities at the local level.

During the drafting of the UNCCD, states explicitly invited participants from communities directly affected by drought and desertification. The intergovernmental negotiating committee tasked with drafting the UNCCD was openly inclusive, as demonstrated by devoting a week to information sharing, and also supporting the participation of NGOs to contribute "constructively to the success of the negotiating process". ${ }^{75}$ Over the course of the negotiations, non-state actors met with state delegations formally and informally and they were successful in convincing governments to propose their ideas. ${ }^{76}$ For example, NGOs argued that national action plans should establish a participatory approach at the international level, and they should be allowed to attend conferences of the parties as observers, or any other decision-making body created. ${ }^{77}$ Both states and NSAs supported the full local participation in decision-making and incorporating an integrated, "bottom-up approach" to combating desertification. ${ }^{78}$ This enabled the

75 United Nations General Assembly Res 47/188 (22 December 1992) UN Doc A/RES/47/188 para 8 .

${ }^{76}$ UNCCD, 'Report of the Intergovernmental Negotiating Committee for the Elaboration of an International Convention to Combat Desertification in Those Countries Experiencing Serious Drought and/or Desertification, Particularly in Africa on Its Second Session' (15 October 1993) UN Doc A/48/226/Add.1 Appendix III Report of Working Group I, para 15 and Appendix III Report of Working Group II, para 15; Michele Merrill Betsill and Elisabeth Corell, 'NGO Influence in International Environmental Negotiations: A Framework for Analysis' (2001) 1 Global Environ Polit 65, 93-94.

${ }^{77}$ ENB, 'Summary of the Second Session of the INC for the Elaboration of an International Convention to Combat Desertification: 13-24 September 1993' (Earth Negotiations Bulletin, 1993) < http://www.iisd.ca/vol04/0422000e.html> accessed 30 January 2015.

78 UNCCD, 'Compilation of Government Views, Statement and Drafting Proposals. Note by the Secretariat' (1993) UN Doc A/AC.241/12; Chasek (n 26) 155 . 
different experiences, needs and values of local communities to inform the negotiations of the UNCCD.

This open participation process was integrated into the legal text of the UNCCD as a central feature of the National Action Plans. These "NAPs" set out the ways in which affected country Parties will respond to the causes and effects of desertification and drought. Articles 9 and 10 emphasise the importance of incorporating bottom-up participatory approaches and specifically refer to women, resource uses, and local communities. ${ }^{79}$ Similarly, the regional annexes to the convention adopt this approach, although to a varying degree. ${ }^{80}$ For example, the Regional Annex for Africa makes direct reference to the role played by women and the importance of their participation, whereas the Regional Annex for Asia is not explicit in their references to the participation by marginalised communities. ${ }^{81}$ These provisions point to states supporting NSA participation in areas that relate to sustainable development and environmental degradation.

Compared to the climate change regime, the UNCCD negotiating process offered more opportunities for non-state actors to contribute to the drafting of the Convention. The conference organisers engaged directly with those communities who were most affected by climate change. Not

${ }^{79}$ UNCCD 1994 arts 9, 10(2), 10(2)(f). See also arts 3, 5(d), 17(1)(f), 18(2)(a), 19(1)(a), 19(3)(b), 21(1)(d), 22(7); Geoffrey Lean, Down to Earth: A Simplified Guide to the Convention to Combat Desertification, Why It is Necessary and What is Important and Different about It (Secretariat of the UN Convention to Combat Desertification 1995) 19; Alon Tal and Jessica A Cohen, 'Bringing "Top-Down" to "Bottom-Up": A New Role for Environmental Legislation in Combating Desertification' (2007) 31 Harv Envtl L Rev 163, 177.

${ }^{80}$ United Nations Convention to Combat Desertification in those Countries Experiencing Serious Drought and/or Desertification, Particularly in Africa, Annex I Regional Implementation Annex for Africa (adopted 17 June 1994, entered into force 26 December 1996) 1954 UNTS 3 arts 4(b), 6(2), 8(2)(c), 11(g); United Nations Convention to Combat Desertification in those Countries Experiencing Serious Drought and/or Desertification, Particularly in Africa, Annex II Regional Implementation Annex for Asia (adopted 17 June 1994, entered into force 26 December 1996) 1954 UNTS 3 art 4(d); United Nations Convention to Combat Desertification in those Countries Experiencing Serious Drought and/or Desertification, Particularly in Africa, Annex III Regional Implementation Annex for Latin America and the Caribbean (adopted 17 June 1994, entered into force 26 December 1996) 1954 UNTS 3 art 4(1); United Nations Convention to Combat Desertification in those Countries Experiencing Serious Drought and/or Desertification, Particularly in Africa, Annex IV Regional Implementation Annex for the Northern Mediterranean (adopted 17 June 1994, entered into force 26 December 1996) 1954 UNTS 3 arts 3(2), 5(d).

${ }^{81}$ UNCCD 1994 Annex I (Africa) art 8(2)(c). 
only does this continue to ensure that disadvantaged voices are heard, but also reflects a plurality of experiences contributing to the evolution of the regime. This openness and the explicit inclusion of traditionally marginalised communities as key participants in NAPs may indicate a commitment to address some of the "isms" of domination criticised by ecofeminists as it enabled voices generally excluded from the international sphere to speak and raise concerns over economic, social and political inequalities which compounded the effects of desertification.

The above analysis indicates that the UNCCD was relatively successful at enabling the voices and experiences of traditionally marginalised and excluded communities to be heard during the negotiating process. This opportunity was transformative because it incorporated inclusive references that obliged state parties to provide for the participation by groups, such as women, who have traditionally been excluded from international institutions. These references mean that women, local communities and indigenous communities are also involved in the subsequent development of policy and institutions related to the UNCCD. However, compared to the UNCCD, the UNFCCC has been slow to enable the voices of traditionally marginalised groups to contribute to the institutional evolution. This is because it omitted certain Major Groups from gaining official observer status. "Major Groups" are the nine sectors of society recognised by Agenda 21 as the main channels through which broad participation would be facilitated in UN activities related to sustainable development. They include, inter alia, Women, Children and Youth, Indigenous Peoples, Business and Industry, and Non-Governmental Organisations. ${ }^{82}$ In order to participate actively in meetings, they need to be granted official observer status according to the provisions of the treaty.

Article 4 UNFCCC places broad obligations on parties to adopt an expanded approach to participation. However, there is no such obligation for the Convention's institutions. ${ }^{83}$ Certain Major Groups were granted official observer status from the outset. These Groups included environmental NGOs, and business and industry NGOs. ${ }^{84}$ Other Major Groups, such as local government and municipal authorities, and indigenous peoples, were granted official recognition in 1995 and 2001 respectively. The Women's Major Group had to wait until 2011 before

\footnotetext{
${ }^{82}$ Agenda 211992 Ch 24-32.

${ }^{83}$ UNFCCC 1992 art 4.

${ }^{84}$ Karen Morrow, 'Integrating Gender Issues into the Global Climate Change Regime' in Susan Buckingham and Virginie Le Masson (eds), Understanding Climate Change through Gender Relations (Routledge 2017).
} 
being granted official recognition by the regime. ${ }^{85}$ To date, the Farmer's Major Group remains subject to provisional recognition. ${ }^{86}$ The delay in officially recognising all major groups indicates a prioritisation and valorisation of voices and experiences from particular backgrounds, such as technology, business and trade.

The slow inclusion of the Women's Major Group and Farmers Major Group gives insight about which voices and whose experiences were valued during the evolution of the climate change regime. It highlights that the international community were slow to recognise gender as an important constituency for responses to climate change in the institutional machinery of the UNFCCC regime ${ }^{87}$ For one thing, it means that the diverse interests, expertise and experiences of women are omitted from the information gathering processes, and from informing the negotiations. Second, without having a platform for women's expertise, interests and experiences, it is more difficult for stakeholders to highlight the interconnecting ways in which climate change disproportionately impacts and affects women and other marginalised communities.

For example, women make up $48 \%$ of the agricultural labour force in developing countries. ${ }^{88}$ This percentage is likely to grow because of the increased feminisation of agriculture as a result of "increased urbanization, the migration of many young men to the cities, commercial farming growth, conflict, and climate change". ${ }^{89}$ Rural women in particular are disproportionately affected by climate change because they undertake a higher proportion of social reproductive work, such as childcare and collecting firewood and water. ${ }^{90}$ The slow recognition of gender as a constituency and the continued failure to officially recognise the Farmers Major Group has a gendered impact, as it excludes the voices and

85 FCCC, 'Non-Governmental Organisation Constituencies' $<$ https://unfccc.int/files/parties_and_observers/ngo/application/pdf/constituency_ 2011 english.pdf $>$ accessed 7 March 2018.

${ }^{86}$ FCCC, 'UNFCCC Constituency Focal Points' Contact Details' (2018). $<$ https://unfccc.int/sites/default/files/resource/constituency_focal_points.pdf $>$ accessed 7 March 2018

${ }^{87}$ For an interesting discussion of this issue see Morrow ( $\mathrm{n} 85$ ).

${ }^{88} \mathrm{FAO}$, 'Why is Gender Equality and Rural Women's Empowerment Central to the Work of FAO' (Gender, 2018) <http://www.fao.org/gender/background/en/> accessed 18 May 2018.

${ }^{89}$ FAO, 'Rural Women: Striving for Gender-Transformative Impacts' (Global Forum on Food Security and Nutrition, 2017) 2.

${ }^{90}$ Christine Jost and others, 'Understanding Gender Dimensions of Agriculture and Climate Change in Smallholder Farming Communities' (2016) 8 Clim Dev 133. 
experiences of people who are disproportionately affected by climate change while also being the closest to the land that is degraded. Nevertheless, as discussed below, there are some signs of change within the UNFCCC, particularly in relation to integrating gender considerations into UNFCCC work.

\section{Integrating a gender perspective: the adoption of Gender Action Plans by the UNCCD and the UNFCCC}

Like the UNCCD, there has been some substantive progress with regards to gender in the UNFCCC after the grant of constituency status for the Women's Major Group in 2011. Unlike the earlier UNFCCC and the 1997 Kyoto Protocol, the 2015 Paris Agreement refers to gender equality and the empowerment of women in its preamble, and in the context of climate change adaptation (article 7) and capacity building (article 11). ${ }^{91}$ Decision 3/CP.23 establishes a Gender Action Plan (GAP) which "recognises the need for women to be represented in all aspects of the UNFCCC process and the need for gender mainstreaming through all relevant targets and goals in activities under the Convention as an important contribution to increasing their effectiveness". ${ }^{92}$ The GAP lists four priority areas: capacity-building, knowledge-sharing and communication; genderbalance, participation and women's leadership; coherence, genderresponsive implementation and means of implementation; and monitoring and reporting. These priority areas reflect the goal of embedding gender considerations into all activities undertaken by the climate change regime.

The GAP provides "quick win" solutions, such as promoting travel funds as a means to support the participation of women in national delegations, and organising and conducting capacity-building training on leadership and negotiation skills. ${ }^{93}$ It aims to enhance the capacity of Parties and stakeholders to develop "gender responsive policies, plans and programmes on adaption, mitigation, capacity-building technology and finance" through, inter alia, workshops and technical assistance. ${ }^{94}$ It also aims to hold a dialogue on the implementation of commitments to integrate gender into areas such as access to finance, technology needs assessments,

\footnotetext{
${ }^{91}$ Paris Agreement arts 11(3)-11(5).

92 Decision 3/CP23 'Establishment of a Gender Action Plan' (17 November 2017) FCCC/CP/2017/11/Add1 Annex para 3.

93 Ibid annex 16.

${ }^{94}$ Ibid annex 16.
} 
and budgeting. ${ }^{95}$ These activities focus on improving the current institutional framework, structures and policies in order to ensure that they are able to respond to gender concerns. The GAP also identifies the need to share experiences in how Parties and observer organisations have promoted the systematic integration of gender considerations into issues such as mitigation and adaptation activities. ${ }^{96}$ These examples indicate that the GAP recognises that stakeholders, such as women's rights organisations, indigenous women representatives and other actors, should be involved to ensure an inclusive and open dialogue. ${ }^{97}$

Nevertheless, the content of the GAP and the Paris Agreement both suggest that state Parties and the institutional machinery of the UNFCCC have not engaged with the conceptual and structural elements of the climate change problem which continue to exclude and devalue women. The activities outlined in the GAP ensure that data is produced and there is a greater understanding of the impact of climate change on gender, but they do not engage with the conceptual and structural barriers that continue to exclude and devalue women within the spheres that are prioritised in the climate change: technology, financing, business, and trade. Instead, the GAP seeks to empower women by integrating gender considerations into all activities of the UNFCCC, which may not offer the opportunity to critique the underlying assumptions that inform these activities, and what they may say about the relationship between humanity and the environment. Therefore, the extent to which it can engage with transformation ecofeminist ethics remains limited.

The UNCCD has also recognised the importance of integrating a gender perspective in the implementation of the Convention. Parties to the UNCCD and stakeholders have acted on gender since 1998 and have repeatedly called for consistent gender balance in civil society participation and within the roster of independent experts. Parties and stakeholders have evaluated the actions in support of women and women's groups, particular those undertaken at the local level. ${ }^{98}$ Building from these reports, the Parties have requested the UNCCD secretariat to promote gender through its policy-advocacy framework, and to mainstream gender issues at different levels and with the involvement of multiple stakeholders. ${ }^{99}$ In

\footnotetext{
95 Ibid annex 17.

${ }^{96}$ Ibid annex 16.

${ }^{97}$ Ibid annex 16.

${ }^{98}$ UNCCD, 'Overview of Gender Mainstreaming in the Implementation of the Convention: 1998-2018' (7 September 2017) ICCD/COP(13)/CRP.1 Part III.

${ }^{99}$ Decision 9/COP11 'Ways of Promoting and Strengthening Relationships with other Relevant Conventions and International Organizations, Institutions and
} 
2017, the COP adopted a decision explicitly acknowledging that mainstreaming gender in the implementation of the Convention will strengthen its effectiveness and efficiency at the local level. ${ }^{100}$

The UNCCD adopts a social reproductive perspective in the Gender Plan of Action (GPA). It identifies that women are "strategic agents of change" 101 and acknowledges the structural inequalities embedded in the "social, political, economic and cultural institutions, norms and practices" that limit women's agency and undermine the effective implementation of the Convention. ${ }^{102}$ In response to these findings, the GPA intends to "make the implementation of the Convention ... gender-responsive and transformative ... by providing guidance to Parties and other actors on policies and measures to mainstream gender ..." 103 The GPA states that women must benefit from any interventions and they should not increase women's burden. ${ }^{104}$

The GPA outlines four key priorities for action, which cover women's participation in decisions to implement the UNCCD, integrating women's economic empowerment in these activities, strengthening women's land rights and access to resources, and enhancing women's access to knowledge and technology. ${ }^{105}$ Mechanisms for implementation include "working with and through women's organisations", developing strategic partnerships, mobilising financial resources, and monitoring and reporting on the interventions. ${ }^{106}$ These provisions are more progressive because they place the barriers to participation in a broader context that takes into account the need to establish foundations for women's empowerment.

Therefore, compared to the GAP, the GPA incorporates a more transformative approach towards gender recognition and gender

\footnotetext{
Agencies' (26 September 2013) ICCD/COP(11)/23/Add1 (2013); Decision 9/COP10 (21 October 2011) ICCD/COP(11)/23/Add1.

${ }^{100}$ Decision 30/COP13 'Gender Equality and Women's Empowerment for the Enhanced and Effective Implementation of the Convention' (15 September 2017) 15 September 2017; UNCCD, 'Draft Advocacy Policy Frameworks: Gender, Drought, and Sand and Dust Storms. Note By The Secretariat' (3 July 2017) ICCD/COP(13)/19.

${ }^{101}$ UNCCD, 'Gender Plan of Action' (n 100) para 10.

102 Ibid para 11; See also Barbara Laslett and Johanna Brenner, 'Gender and Social Reproduction: Historical Perspectives’ (1989) 15 Annu Rev Sociol 381; Patricia E Perkins, 'Feminist Ecological Economics and Sustainability' (2007) 9 Journal of Bioeconomics 227

${ }^{103}$ UNCCD (n 100) para 14.

104 Ibid para 16.

105 Ibid para 17.

106 Ibid paras 18-21.
} 
mainstreaming in the UNCCD. This is because it starts from a position which recognises the structural barriers faced by women. Unlike the UNFCCC, which focuses on improving existing institutional processes and developing ways to incorporate women within them, the GPA focuses on the local level and addressing barriers to implementation there. Furthermore, by approaching the barriers facing women from a social reproductive perspective, the GPA has adopted a more critical and nuanced perspective from which to start. This indicates a greater engagement with the problems faced by women experiencing drought and desertification.

The above comparison of the treatment of women within the two regimes indicates that the UNCCD incorporates more transformational participatory provisions than the UNFCCC. The UNCCD recognises that different communities and members of society are disproportionately affected by drought and desertification, depending on a number of factors. It has embedded inclusive participation within its provisions, the NAPs and within the institutional structure itself. It recognises and values the experiences of marginalised communities, particularly women, and as such, the participation reflects a bottom-up approach to developing and implementing the agreement. Therefore, these provisions indicate a more transformative approach to responding to drought and desertification because they enable the experiences, needs and values of women to inform the evolution of the regime.

However, with the recognition that gender is an important constituent of climate change and with the introduction of the Gender Action Plan, the UNFCCC may be "catching up" to the UNCCD. As it currently stands, the focus of the climate change regime is integration and mainstreaming gender considerations across all work streams. This focus does not allow much opportunity to engage in more conceptual and transformational debate about why women and other marginalised communities are disproportionately affected, what that says about human/non-human relationships understood within the regime, and what this may tell us about current strategies towards responding to the issue.

\subsubsection{Integrating ecosystems services into the regimes: reinforcing the human/nature divide?}

Ecofeminist ethics also acknowledge that humanity is embedded within ecological systems, rather than separate and distanced from it. ${ }^{107}$ For ecofeminism, any international regime or legal agreement that recognises

${ }^{107}$ Mary Mellor, 'Feminism and Environmental Ethics: A Materialist Perspective' (2000) 5 Ethics \& the Environment 107; Mellor, Feminism \& Ecology (n 44). 
the embeddedness of humanity in non-human nature would be transformational. However, very little IEL includes strong language that acknowledges the embeddedness of humanity within a broader ecological system. Instead, it emphasises the second aspect of this relationship, namely that humanity is different and distinct from non-human nature and adopts an anthropocentric worldview.

This anthropocentric worldview places human beings and their interests as the central consideration when addressing environmental concerns. It legitimises the exploitation of non-human nature because it is seen as other, separate and distinct from humanity. Val Plumwood extends this critique and argues that historically, anthropocentrism and androcentricsm have been "intimately connected" within the western philosophical tradition. ${ }^{108}$ Androcentricsm refers to "male-centred thinking that assumes the superiority of men over women," that "naturalises and justifies a certain sort of self-centredness, self-imposition, and dispossession, [and] provides... a very distorted framework for perception of the other." ${ }^{109}$ An anthropocentric framework is built on logical structures which create a "false universalism in culture in which the experiences of the dominant "centre" are represented as universal, and the experiences of those subordinated in the structure are rendered as secondary, or irrational". ${ }^{110}$ Applying this analysis to the context of IEL, the emphasis of difference and othering, also enables non-human nature to be translated into commodities or entities and objects that serve a purpose or function for the benefit of (certain categories of) humanity.

\section{Incentivising conservation through the commodification of nature}

One way in which this perspective has been incorporated within the two environmental regimes is through the introduction of "ecosystem services" as way to incentivise the conservation of important ecological functions that are necessary for the survival of humanity. ${ }^{111}$ Ecological functions are the "interacting biological, chemical and physical processes that underpin

108 Val Plumwood, 'Nature, Self and Gender: Feminism, Environmental Philosophy, and the Critique of Rationalism' (1991) 6 Hypatia 3, 22.

109 Val Plumwood, Environmental Culture: The Ecological Crisis of Reason (Routledge 2002) 118.

110 Ibid 99.

111 Jose Puppim de Oliveira and others, Governing the Forests: An Institutional Analysis of REDD + and Community Forest Management in Asia (United Nations University and International Tropical Timber Organization 2013) 1. 
the provision of ecosystem services". ${ }^{112}$ Ecosystem services are understood as "the benefits that people obtain from ecosystems". ${ }^{113}$ They include provisioning, regulating, cultural, and supporting services - all of which are defined in relation to humanity. ${ }^{114}$ Payment for ecosystem services (PES) are schemes that incentivise the conservation of ecological services for future generations while also promoting economic growth and development in developing countries. ${ }^{115}$

The concept of ecosystem services has been incorporated within the climate change regime in the context of land use, land-use change and forestry activities. ${ }^{116}$ In 2007, the COP adopted the Bali Action Plan which outlined a commitment to consider "policy approaches and positive incentives on issues relating to reducing emissions from deforestation and forest degradation in developing countries; and the role of conservation, sustainable management of forests and forest carbon stocks in developing countries". ${ }^{117}$ Subsequent COP decisions refined the reducing emissions from deforestation and forest degradation (REDD) mechanism and made the financial incentivisation more explicit. ${ }^{118}$ This is a voluntary climate change mitigation approach that incentivises developing countries to reduce emissions from deforestation and forest degradation.

The Paris Agreement incorporates REDD + and the concept of ecosystem services in article 5. This provision encourages parties to "take action to implement and support, including through results-based

112 Barron J Orr and others, 'Scientific Conceptual Framework for Land Degradation Neutrality: A Report of the Science-Policy Interface.' (UNCCD-SPI Technical Series No.01, 2017) 13.

113 Ibid; Walter V Reid and others, Ecosystems and Human Well-Being: Synthesis (Island Press 2005).

${ }^{114}$ Orr and others (n 112) 13.

${ }^{115}$ Wilkinson, 'Payment for Ecosystem Services' (n 53) 169.

${ }^{116}$ UNFCCC 1992 art 4(1)(d); Kyoto Protocol art 2.

117 Decision 1/CP13 'Bali Action Plan' (14-15 December 2007) FCCC/CP/2007/6/Add1* para 1(b)(iii).

118 Decision 2/CP15 'Copenhagen Accord' (18 December 2009) FCCC/CP/2009/11/Add1; Decision 1/CP16 'The Cancún Agreements: Outcome of the Work of the Ad Hoc Working Group on Long-term Cooperative Action under the Convention (10-11 December 2010) FCCC/CP/2010/7/Add1; Decision 2/CP17 'Outcome of the Work of the Ad Hoc Working Group on Long-Term Cooperative Action under the Convention' (11 December 2011) FCCC/CP/2011/9/Add1; See also FCCC, 'Report of the Ad Hoc Working Group on Long-Term Cooperative Action under the Convention on Its Eighth Session, Held in Copenhagen from 7 to 15 December 2009' (5 February 2010) FCCC/AWGLCA/2009/17. 
payments, the existing framework as set out in related guidance and decisions already agreed under the Convention". ${ }^{119}$ Therefore, while the Agreement does not explicitly refer to PES, it does include references to incentivising states through economic reward to conserve and protect important ecological functions.

Current negotiations under the Paris Agreement indicate that REDD+ will be incorporated into developing countries' intended nationally determined contributions (INDCs), as well as voluntary cooperation. ${ }^{120}$ The continued integration of results-based payments, PES and ecosystem services highlights that that the anthropocentric worldview, with its underlying value dualism that separates human/nature thus legitimising the commoditisation of nature, continues to inform international responses to climate change mitigation. This perception of the environment is further reflected in the language in the Paris Agreement, which refers to forests as "sinks" or reservoirs for greenhouses gases. This is a reductive view of the environment, which views non-human nature as a "sink", and something to be used for human interests, rather than recognises that human activities are embedded and reliant on continued ecological functions of ecosystems. The extension of this worldview is the assumption that communities need to be "incentivised" or "rewarded" for its conservation.

This anthropocentric worldview is not restricted to the climate change regime. The desertification regime also promotes the use of ecosystem services as a solution to protect degrading ecosystems while maintaining economic growth and achieving sustainable development objectives. The UNCCD has embedded the concept of ecosystem services into many of its strategies for achieving the objectives of the Convention.

One of the strategic objectives of the desertification regime is to improve land productivity and related ecosystem services. ${ }^{121}$ In the context of the UNCCD, the goal of land degradation neutrality refers to the goal of maintaining or enhancing the "stocks of natural capital associated with land resources and the ecosystems that flow from them." 122 In this conceptual framework, ecosystem functions have been transformed into "services" that

\footnotetext{
119 Paris Agreement art 5(2).

${ }^{120}$ FCCC, 'Non-Market-Based Approaches: Technical Paper' (24 November 2017) FCCC/TP/2014/10; see also Peter Graham, 'Cooperative Approaches for Supporting REDD+: Linking Articles 5 and 6 of the Paris Agreement' (Climate Advisors, 2017) 6.

${ }^{121}$ Decision 7/COP13 'The Future Strategic Framework of the Convention' (15 September 2017) ICCD/COP(13)/21/Add1 Annex part III.

${ }^{122}$ Orr and others (n 112) 3.
} 
can be "delivered" in order to achieve sustainable food production. ${ }^{123}$ These services are performed for the benefit of human kind, particularly as an "engine of economic growth and a source of livelihood for billions worldwide". ${ }^{124}$ Thus, ecosystem services are explicitly defined as the "benefits" humanity obtains from ecosystems. ${ }^{125}$ More generally, nonhuman nature is referred to as "natural capital" that can be harnessed for sustainable development. ${ }^{126}$ This language, informed by economics, highlights the underlying logic that places humanity at the centre, and associated functions are defined in terms of humanity's needs.

The concept of "ecosystem services" itself is "indicative of an exploitative and androcentric construction of the living order which continues to perpetuate a hierarchical way of thinking that separates humans from nature and reduces nature as subordinate". ${ }^{127}$ As I have argued elsewhere, by redefining ecological functions as services, international policy and discourse "recasts nature as providing a "service" to humanity, without any interrogation of the gendered and exploitative ideology implicit in the language". ${ }^{128}$ In addition, it may be seen as a manifestation of economic rationalism because it seeks to translate the protection of the environment itself into an economic process, thereby disembedding ecosystems themselves. The above examples from both regimes reveal that the conceptual frameworks and logical structures informing these policies continue to view the environment as separate and subordinate, therefore legitimising its exploitation and reinforcing its value as a commodity or resource for economic gain.

The preceding comparison between the UNFCCC and the UNCCD highlights that both incorporate anthropocentric and androcentric perspectives towards non-human nature. Both regimes have incorporated the concept of ecosystem services as ways in which to achieve the objectives of the regimes. It has highlighted how this concept positions humans as central and non-human nature as subordinate and as a resource to be used for human purposes. Therefore, the extent to which these two

\footnotetext{
123 Ibid.

${ }^{124}$ UNCCD, 'Land and Sustainable Development Goals' (ND)

$<$ https://www.unced.int/issues/land-and-sustainable-development-goals> accessed 23 March 2018.

${ }^{125}$ Decision 7/COP13 The Future Strategic Framework of the Convention Annex 19.

${ }^{126}$ Orr and others (n 112); UNCCD, 'Land and Sustainable Development Goals' (n 124).

${ }^{127}$ Wilkinson, 'Payment for Ecosystem Services' (n 53) 169.

128 Ibid fn 7.
} 
regimes are transformational or incorporate ecofeminist ethics in this context is limited.

\subsection{Comparing approaches towards science and technology in the UNFCCC and UNCCD: do they recognise context or location?}

Both the UNCCD regime and the UNFCCC prioritise scientific cooperation, technological assistance and transfer, and addressing the impact of environmental degradation on commercial activities. However, the way in which these areas are integrated into the regimes, and the justifications for their integration are different. These variances include the subject matter, recognition of the broader context of the environmental issue, and the type of actors involved in the negotiations. The analysis suggests that these two regimes demonstrate a sense of optimism about technological innovation and commit to a future potential where science, technology and know-how will be able to mitigate environmental degradation and enable communities to adapt to existing environmental problems, while also allowing states to continue to develop through exploitative production. This optimistic outlook on the role of science and technology fails to take into account how mechanised science and the global market economy is informed by the logical structures which view women and non-human nature as "other" and objects for exploitation, to the detriment of all communities.

\subsubsection{Prioritising science, technology and commerce}

The UNFCCC has prioritised the consideration of scientific, commercial, and technological implications of climate change. This is reflected within the negotiations of the UNFCCC and in the subsequent evolution of the regime. During the negotiations of the UNFCCC, Austria and Switzerland proposed that the commitments in the Convention should promote the "development and transfer of environmentally sound technologies, and technical as well as financial assistance." 229 Other parties also supported the inclusion of cooperation by "means of systematic and

${ }^{129}$ FCCC, 'Compilation of Proposals Related to Commitments Submitted by the Bureau of Working Group I' (15 August 1991) A/AC.237/Misc.7 Part A(I.1) 3-4; FCCC, 'Preparation of a Framework Convention on Climate Change: Set of Informal Papers Provided by Delegations, Related to the Preparation of a Framework Convention on Climate Change. Addendum' (22 May 1991) UN Doc A/AC.237/Misc.1/Add.1 7. 
sustained research ... in order to better understand the causes and impacts of climate change and the response strategies required to deal with such change." 130 These examples highlight that the need to understand the issue of climate change was directly linked to the need to prove that it was a problem that required global action to counteract.

One reason for emphasising the importance of continued scientific understanding of climate change is the need to overcome obstacles in the negotiating process. The causes of climate change are deeply embedded in all aspects of the world's economic and social activities from the developed to the developing world. These activities include transportation, industry, international trade, agriculture, fishing and forestry practice, to name a few. ${ }^{131}$ Climate change scepticism meant that there was reluctance to commit to reducing emissions because of the detrimental impact on all aspects of society, until there was certainty of the existence of climate change and that it would have a destructive effect on societies. ${ }^{132}$ State submissions during the negotiations of the UNFCCC indicate that scientific and technical cooperation were central features of the future climate change regime, both to enable buy-in from reluctant states, and as a way to maintain and consolidate cooperation.

The climate change regime has continued to emphasise the role of science and technology as a way to consolidate cooperation within the regime. Systematic observation of the climate system is seen as the "the foundation for our understanding of climate change and its associated impacts, and helps scientists determine future trends" 133 while also being a way in which Parties can cooperate in data gathering and systematically observing the climate system. ${ }^{134}$ Similarly, Article 4(1) UNFCCC calls for parties to "promote and cooperate in the development, application and

${ }^{130}$ FCCC, 'Compilation of Proposals Related to Commitments, A/AC237/Misc7' (n 130) Part A (I.1) 6; French Republic, 'Alternative Proposal for Annex I (Research and Development and Systematic Observation) Contained in a Revised Single Text on the Elements Relating to the Mechanisms (A/AC.237/Misc.13) Submitted by the Co-Chairmen of Working Group II' (17 December 1991) A/AC.237/WG.II/CRP.71(a), 2(a), 3.

${ }^{131}$ James K Sebenius, 'Designing Negotiations Toward a New Regime: The Case of Global Warming' (1991) 15 Int Security 110, 121.

132 Daniel Bodansky, 'The United Nations Framework Convention on Climate Change: A Commentary’ (1993) 18 Yale JInt'1 L 451, 476.

${ }^{133}$ FCCC, 'Science in the Negotiations' (ND)

$<$ https://unfccc.int/topics/science/the-big-picture/science-in-the-negotiations> accessed 14 May 2018.

${ }^{134}$ UNFCCC 1992 art 5; see also Paris Agreement arts 4, 7. 
diffusion, including transfer, of technologies...that control, reduce or prevent anthropogenic emissions of greenhouse gases..." ${ }^{135}$ Subsequent COP decisions and legal agreements have similarly affirmed the potential of sci-tech to provide the foundation of our understanding of the issues, and also as a way to "improve resilience to climate change and to reduce greenhouse gas emissions". ${ }^{136}$

The focus within the climate change regime on addressing science and technology indicates that many participants in the negotiation process viewed climate change as primarily scientific and technical in nature and therefore resolvable through innovation. ${ }^{137}$ This is an optimistic view of the role of science and technology in which current, potential, and future developments will be able to "solve" or "fix" the harm that humanity has caused, while maintaining the overarching goals of economic growth, poverty eradication and sustainable development. This view is reflected in the UNFCCC and the Kyoto Protocol, which associated the promotion of sustainable development with the development and transfer of new technologies to mitigate and adapt to the effects of climate change while also ensuring the sustainable economic development of party states. ${ }^{138}$ During the subsequent evolution of the climate change regime, COP decisions have introduced new financial and trade mechanisms to support technical development for climate change mitigation and adaptation, and article 10 of the Paris Agreement explicitly states that technology and scientific innovation is "critical for an effective, long-term global response to climate change and promoting economic growth and sustainable development". ${ }^{139}$ These examples indicate that the content of COP

\footnotetext{
${ }^{135}$ UNFCCC 1992 art 4(1)(c).
}

${ }^{136}$ Paris Agreement art 10(1).

${ }^{137}$ E.g. FCCC, 'Strengthening the Commitments in Article 4.2(A) and (B) Policies and Measures: Synthesized List of Policies and Measures Identified by Annex I Parties in Their National Communications. Note by the Secretariat' (23 October 1995) annex 4-5; FCCC, 'Synthesis of Proposals by Parties. Note by the Chairman' (19 November 1996) FCCC/AGBM/1996/10 para 13; FCCC, 'Ideas and Proposals on the Elements Contained in Paragraph 1 of the Bali Action Plan: Submissions from Parties' (27 October 2008) FCCC/AWGLCA/2008/MISC.5 10-11 (Argentina), 26-27 (Brazil), 29.

${ }^{138}$ E.g. UNFCCC 1992 arts 4(1), 5; Kyoto Protocol arts 2, 10(c), 10(d).

139 Paris Agreement art 10(5); see also Cancún Agreements LCA preamble, paras 71, 120(a), see in general Part IV(B); FCCC, 'Informal Note by the Co-Facilitators' (13 November 2017) SBSTA47.IN.2; FCCC, 'Initial Draft of the Technology Framework. Informal Document by the Chair' (15 March 2018) SBSTA48.Informal.15. 
decisions and Agreements continues to associate potential technological and scientific advances that allow for continued economic growth in the context of sustainable development.

The UNCCD also incorporates a significant number of references to scientific and technological advancements in relation to drought and desertification. Under article 17, parties undertake to "promote technical and scientific cooperation in the fields of combating desertification and mitigating the effects of drought". ${ }^{140}$ Similarly, under article 18, parties undertake to "promote, finance and/or facilitate the financing of the transfer ... adaptation and development of environmentally sound, economically viable and socially acceptable technologies relevant to combating desertification and/or mitigating the effects of drought". ${ }^{141}$ Thus far, the two environmental regimes demonstrate similar commitments to the promotion of technology and science as a way to ensure cooperation and to support the ability of developing countries to achieve their obligations under the convention.

Both the legal regimes demonstrate a level of "techno-optimism" 142 by which I mean that actors within the regimes champion the potential of science and technology to repair and alleviate environmental damage. ${ }^{143}$

\footnotetext{
${ }^{140}$ UNCCD 1994 art 17(1).

${ }^{141}$ Ibid art 18(1).

142 Plumwood, Environmental Culture (n 109) 39.
}

143 The benefits or otherwise of technology are intimately linked with wider debates surrounding economic growth, capitalism and other social institutions. There is insufficient space in this article to fully develop this line of critique, but for recent examples of a techno-optimistic worldview, see Arthur PJ Mol and Gert Spaargaren, 'Ecological Modernisation Theory in Debate: A Review' (2000) 9 Environmental Politics 17; John Asafu-Adjaye et al, 'An Ecomodernist Manifesto' (Ecomodernism, 2015) <http://www.ecomodernism.org/manifesto-english/> accessed 10 August 2018; Christian Kerschner et al, 'Degrowth and Technology: Towards Feasible, Viable, Appropriate and Convivial Imaginaries’ (2018) 197 J Clean Prod 1619.; for literature interrogating this worldview from other fields, see eg James E Krier and Clayton P Gillette, 'The Un-Easy Case for Technological Optimism Essay' (1985) 84 Mich L Rev 405; Herman E Daly and John B Cobb, For the Common Good: Redirecting the Economy Toward Community, the Environment, and a Sustainable Future (Beacon Press 1994); Dana R Fisher and William R Freudenburg, 'Ecological Modernization and Its Critics: Assessing the Past and Looking Toward the Future' (2001) 14 Soc Nat Resour 701; Herman E Daly, 'Reconciling the Economics of Social Equity and Environmental Sustainability' (2002) 24 Popul Environ 47; Christian Kerschner and Melf-Hinrich Ehlers, 'A Framework of Attitudes Towards Technology in Theory and Practice' (2016) 126 Ecol Econ 139; Rika Preiser et al, 'Navigating Alternative Framings of 
Ecofeminists are resistant to the narrative that science and technology can achieve this feat. ${ }^{144}$ This resistance stems from their critique of science and its associated mechanistic analysis of reality. This new definition of reality is based on assumptions of ontology, epistemology, context independence and identity that is analogous to the structure of machines. They argue that this mechanistic understanding of reality is the "legitimising ideology of industrial capitalism and its inherent ethic of the domination of nature." 145 From the scientific revolution onwards, science has viewed as "objective, value-free, context-free knowledge of the external world." ${ }^{146}$ Like machines, order and power are integral components of this mechanical worldview and sanctioned the management of both nature and society. ${ }^{147}$ Thus, nature is ripe to be transformed or altered for the needs and benefit of humanity, or more specifically, the needs of men. ${ }^{148}$ Ecofeminists argue that this mechanistic worldview, which renders nature as inert and passive has completed infiltrated and reformed human consciously completely so that we rarely question its validity. ${ }^{149}$

The impact of this worldview is that nature, humans and society are seen to be made up of interchangeable parts that can be externally repaired or replaced. It allows humans to remain outside of nature, as intellectual beings who calculate the maximum satisfaction or utility of nature. Plumwood argues that in this worldview, other species appear through a "reductive and human-centred framework, in a rationalised and commodified form." 150 This worldview also informs capitalist economics, which have "beatified a contractual, privileged and rationally "autonomous" master subject" who is separate from, and above nature. ${ }^{151}$ From this, it can be argued that the focus on science and technological

Human-Environment Interactions: Variations on the Theme of "Finding Nemo"" (2017) 20 Anthropocene 83; Armin Grunwald, 'Diverging Pathways to Overcoming the Environmental Crisis: A Critique of Eco-Modernism from a Technology Assessment Perspective' (2018) 197 J Clean Prod 1854.

${ }^{144}$ Ariel Salleh, Ecofeminism as Politics: Nature, Marx and the Postmodern (2nd edn, Zed Books 2017).

145 Carolyn Merchant, Radical Ecology: The Search for a Liveable World (Routledge 1992) 59.

146 Ibid 55.

${ }^{147}$ Merchant (n 145) 55.

148 Merchant (n 145); Mary Mellor, 'Women, Nature and the Social Construction of "Economic Man"” (1997) 20 Ecolog Econ 129.

149 Merchant (n 145) 48.

${ }^{150}$ Plumwood (n 109) 27.

151 Ibid. 
innovation displayed in the UNFCCC and UNCCD can be interpreted as the desire to fix ecological malfunctions in order to maintain "the smooth functioning of industry and bureaucracy..." 152 which allows certain privileged forms of humanity to remain outside of nature, as intellectual beings and benefit from the embedded and embodied labour of non-human nature and women.

The preceding discussion argues that the mechanistic worldview privileges objective, value-free and context-free knowledge, which has legitimised the exploitation of non-human nature and human others associated with nature. While the UNCCD does embody aspects of this worldview through its uncritical promotion of technological cooperation and advancement, it also includes provisions that take into account the context in which science and technology will be used by local communities and local populations. Under article 17, the Parties to the UNCCD should support research activities that address specific needs of local populations and "lead to the ... implementation of solutions that improve the living standards of people in affected areas." ${ }^{153}$ Similarly, research activities should "protect, integrate, enhance and validate traditional knowledge and local knowledge..." 154 With regards to technology development and transfer, Parties shall "facilitate access ... on favourable terms ... to technologies most suitable to practical application for specific needs of local populations, paying special attention to the social, cultural, economic and environmental impact of such technology." 155 It also calls for the protection of traditional and local technology, knowledge and practices. ${ }^{156}$ In addition, the connection between technology transfer and local communities" participation is also reaffirmed in article 10, which introduces the National Action Programmes (NAP). It states that NAPs shall promote policies and institutional frameworks that "develop cooperation and coordination, in a spirit of partnership, between the donor community, governments at all levels, local populations and community groups, and facilitate access by local populations to appropriate information and technology." 157 These examples highlight that the focus for the use of such technology is on the local populations and that parties should take into

\footnotetext{
152 Merchant (n 145) 48; Plumwood (n 109) 26.

${ }^{153}$ UNCCD 1994, art 17(1)(b).

${ }^{154}$ UNCCD 1994, art 17(1)(c).

${ }^{155}$ UNCCD 1994, art 18(1)(b).

156 Ibid.

${ }^{157}$ UNCCD 1994, art 10(2)(e).
} 
account the context in which such technology and scientific improvements will be used. ${ }^{158}$

\subsubsection{Recognising interactions between communities and technology}

Furthermore, the subsequent evolution of the UNCCD indicates that there is increasing recognition of the differences in values, principles, and experiences of the environment that may alter the ways in which "other" communities perceive and use the environment. One particular example is the references to the "special relationship" between indigenous peoples and local communities and their environment. The Committee for the Review of the Implementation of the Convention (CRIC) acknowledged the potential cultural and socioeconomic implications of desertification and drought strategies. ${ }^{159}$ The reports include the recognition that initiatives for natural resource management should respect cultural specificities, while also "promoting the customary land tenures of local communities, [and] strengthening and legalizing their traditional institutions." ${ }^{160}$ Similarly, more recent decisions have encouraged parties to take "action at a specific spatial scale so as to address the local ecological and socio-economic conditions in a more holistic manner." 161 These statements indicate that, in the context of the desertification regime, some parties recognise that desertification and drought strategies may marginalise some communities. By explicitly linking management strategies to cultural specificities, these

${ }^{158}$ For feminist analysis of the 'scientisation' of climate change and the need to integrate public deliberation, communication and participation as vital components of responses to climate change, see Karin Bäckstrand, 'Civic Science for Sustainability: Reframing the Role of Experts, Policy-Makers and Citizens in Environmental Governance' (2003) 3 Global Environ Polit 24, 29; Karin Bäckstrand, 'Scientisation vs. Civic Expertise in Environmental Governance: EcoFeminist, Eco-Modern and Post-Modern Responses' (2004) 13 Environ Polit 695, 696-98; For feminist criticisms of science and technology see, Donna Haraway, 'Situated Knowledges: The Science Question in Feminism and the Privilege of Partial Perspective' (1988) 14 FSt 575; Sandra G Harding, Is Science Multicultural? Postcolonialisms, Feminisms, and Epistemologies (Indiana University Press 1998).

${ }^{159}$ UNCCD, 'Report of the Committee for the Review of the Implementation of the Convention on Its First Session' (17 January 2003) ICCD/CRIC(1)/10, para 35. ${ }^{160}$ UNCCD, 'Report of the Committee for the Review of the Implementation of the Convention on Its Fifth Session' (24 April 2007) ICCD/CRIC(5)/11*, para 84. ${ }^{161}$ Decision 1/COP6 'Further Steps in the Implementation of the Convention' (3 September 2003) ICCD/COP(6)/11/Add1(2003), para 9. 
references take into account the differences between communities and groups.

The language in the UNFCCC regime reflects a more dispassionate and technical approach towards embedding technology within communities. Many of the COP decisions relating to technology transfer focus on epistemic communities separate and above local communities. For example, in Decision 1/CP.21, the parties request the "Technology Executive Committee and the Climate Technology Centre and Network" to "engage in the technical expert meetings and enhance their efforts to facilitate and support Parties in scaling up the implementation of policies, practices and actions identified during this process." 162 The Paris Climate Agreement similarly states that "Parties share a long-term vision on the importance of fully realizing technology development and transfer in order to improve resilience to climate change." 163 These examples indicate that the climate change regime has not yet properly engaged in the ways in which the focus on technology and science is disembedded and disembodied from the ecological world and communities. ${ }^{164}$ This means that such initiatives are unlikely to be effective unless the focus becomes more embodied within the ecological world.

However, recent publications indicate that UNFCCC institutions are integrating a more contextual approach towards science and technology implementation. For example, the GAP identifies that gender-responsive climate policy should be strengthened through technology development and transfer. ${ }^{165}$ Technology and capacity building have been identified as priority areas, and will be incorporated into technology needs assessments. ${ }^{166}$ Finally, the GAP also calls for submissions on the integration of gender considerations into technology and finance policies to be sex-disaggregated and provide a gender analysis. ${ }^{167}$ These examples highlight that the parties are starting to recognise that different communities, members of communities and groups use technology in different ways. Therefore, understanding the context in which technology and know-how will be rolled out is central to developing effective mitigation and adaptation strategies. Similarly, Decision 2/CP.23

\footnotetext{
162 Decision 1/CP21 Adoption of the Paris Agreement, para 109(c)(i).

163 Paris Agreement, art 10(1).

164 Noémi Gonda, "Climate Change, "Technology" and Gender: "Adapting Women" to Climate Change with Cooking Stoves and Water Reservoirs' (2016) 20 Gend Technol Dev 149.

${ }^{165}$ Decision 3/CP23 Establishment of a Gender Action Plan, 13.

166 Ibid 17.

${ }^{167}$ Ibid 18.
} 
recognises the need to strengthen the technologies of local communities and indigenous peoples in a holistic and integrated manner. ${ }^{168}$ This approach, which focuses on knowledge sharing and the exchange of experiences, suggests that the UNFCCC may be starting to take into account the differences between communities and groups based on their specificities.

The preceding discussion compared two manifestations of context within the UNFCCC and the UNCCD. The first compared how the two regimes referred to science and technology within their foundational legal texts. Both regimes emphasise the importance of science and technology to "solve" or "mitigate" the consequences of environmental degradation. This demonstrated a sense of "technological optimism" that is embedded within the mechanistic worldview criticised by ecofeminism because it reduces non-human nature to something inert and dead, thus allowing its exploitation for the pursuit of industry and capitalism. This allows certain privileged groups of humanity to remain outside of nature, as enlightened, intellectual beings who benefit from the embedded and embodied labour of non-human nature and (some) women.

Nevertheless, compared to the UNFCCC, the UNCCD regime has recognised that science and technology development should take into account the context in which they will be used. The provisions in the UNCCD explicitly refer to the location, peoples and communities who will be using and adapting the technology. In this way, the regime embodies some aspects of ecofeminist ethics by recognising that the cultural and historic specificities of groups affect how the technologies are integrated and impact on their daily lives.

This comparison suggests that the UNCCD regime has generally been more aware of context in how it integrates considerations of science and technology within its legal framework. Nevertheless, both regimes demonstrate a continued affirmation that science and technology are the primary solutions to existing environmental problems, without recognising that the assumptions informing these types of knowledge are based on a view of non-human nature and associated human communities as resources and commodities to be exploited for the benefit of humankind.

\subsection{Attending to and respecting difference in the UNFCCC and the UNCCD}

The final lens of the analytical framework extends the above analysis even further and explores how the two regimes pay attention to and respect

${ }^{168}$ Decision 2/CP23 'Local Communities and Indigenous Peoples Platform' (17 November 2017) FCCC/CP/2017/11/Add1, 11. 
difference between different groups. The following comparison explores how the two regimes seek to balance the often-competing interests of equity and historical responsibility for environmental degradation, economic development, and difference in capabilities in performing obligations within environmental regimes.

\subsubsection{Respecting difference: integrating common but differentiated responsibilities in the two regimes}

These tensions are embodied in the principle of common but differentiated responsibilities (CBDR) and its articulation in the climate change regime as common but differentiated responsibilities and respective capabilities (CBDRRC). CBDR recognises extra-legal differences among states" and makes "room for substantive equity in international environmental regimes." 169 Comparing how this principle has been integrated into the two environmental regimes demonstrates that both environmental regimes recognise and respect the pluralities amongst countries by taking into account economic and historically driven differences between countries. However, the extent to which more recent iterations of CBDR demonstrate the transformative potential of ecofeminist ethics is less certain.

The two regimes recognise difference and pluralities of experience by acknowledging the historic responsibility for environmental degradation and the resulting economic inequalities that impair developing countries from implementing their objectives. CBDR/CBDRRC contains two dimensions: that all states are to participate and do their share to ameliorate global environmental problems (common responsibility), and second that some states are in a much better position than others to provide the resources to addresses environmental problems. ${ }^{170}$ Therefore, it integrates references to historic responsibility of developed states while also basing the future contributions by developing countries on their capabilities. In doing so, it tries to reconcile the need for universal action to combat global problems and the need to be sensitive to individual states" special and relevant circumstances. The integration of differences and, to some extent, the acknowledgement of structural inequalities between states, embodies plurality because they pay attention to, and respect differences between the

169 Tuula Honkonen, 'The Development of the Principle of Common but Differentiated Responsibilities and Its Place in International Environmental Regimes' in Tuomas Kuokkanen et al (eds), International Environmental LawMaking and Diplomacy: Insights And Overviews (Routledge 2016) 160.

${ }^{170}$ Ibid 160-61. 
parties, while acknowledging that there are still connections through the shared responsibilities to respond to environmental problems.

\section{Analysing the transformative potential of CBDRRC in the UNFCCC}

CBDRRC is explicitly integrated into the climate change regime as one of its guiding principles. Article 3(1) UNFCCC states that Parties should protect the climate system "on the basis of equity and in accordance with their common but differentiated responsibilities and respective capabilities" and "the developed country Parties should take the lead in combating climate change and the adverse effects thereof." 171 This "radical differentiation" has been reinforced within the Kyoto Protocol and in the Paris Agreement, albeit in a different format. ${ }^{172}$

The Kyoto Protocol includes explicit and implied references to CBDRRC within its text. ${ }^{173}$ It differentiates between developed countries, and between developed and developing countries in terms of the targets they should achieve, ${ }^{174}$ and also in terms of the compliance and enforcement mechanisms. ${ }^{175}$ This differentiation placed a firewall between developed and developing countries within the Protocol, which has been softened in the subsequent evolution of the regime and the Paris Agreement. ${ }^{176}$ Article 2(2) of the Paris Agreement reflects a more qualified understanding of differentiation. It refers to "equity and common but differentiated responsibilities and capabilities, in the light of different national circumstances." ${ }^{\prime 17}$ In this way, differentiation can be interpreted in light of contemporary economic realities, and thus has evolved to take

${ }^{171}$ UNFCCC 1992, art 3(1).

172 Decision 1/CP1 (7 April 1995) FCCC/CP/1995/7/Add, paras 2(a), 2(b); Kyoto Protocol, arts 3, 5, 7, 8, 10(1); Clare Breidenich et al, 'The Kyoto Protocol to the United Nations Framework Convention on Climate Change' (1998) 92 AJIL 315; Joanna Depledge, 'Tracing the Origins of the Kyoto Protocol: An Article-ByArticle Textual History' (25 November 2000) FCCC/TP/2000/2 42.

173 Kyoto Protocol preamble, art 10(1); see also Decision 1/CP1 The Berlin Mandate, paras 2(a), 2(b).

174 Kyoto Protocol, arts 3, 5, 7, 8 .

${ }^{175}$ Decision 27/CMP1 'Procedures and Mechanisms Relating to Compliance under the Kyoto Protocol' (9-10 December 2005) FCCC/KP/CMP/2005/8/Add3 (2005); Bodansky et al (n 29) 167.

176 Hermann E Ott, 'The Kyoto Protocol: Unfinished Business' (1998) 40 Environment: Science and Policy for Sustainable Development 16; Depledge (n 173) 42.

${ }^{177}$ Paris Agreement, art 2(2). 
account of the concerns about CBDRRC by developed countries. ${ }^{178}$ Therefore, the differentiation embedded in the Paris Agreement is more nuanced, but still remains focused on the economic capacity of states.

The operationalisation of the Paris Agreement is through the preparation, communication and maintenance of contributions towards the overall purpose of the Agreement. ${ }^{179}$ These are known as "NDCs" and are expected to progress every five-year cycle. ${ }^{180}$ Intended NDCs are based upon a bottom-up, pluralised response that takes into consideration the structural, institutional, economic and social differences between states which affect their ability to contribute to global climate change reductions. These obligations allow individual countries to "self" determine how their contribution reflects "its highest possible ambition" and the principle of CBDRRC. ${ }^{181}$ By allowing individual countries to determine their contributions, the Agreement recognises that developed and developing countries are starting at different points and thus allows self-differentiation between them and that differentiation will continue over successive cycles of NDCs. Nevertheless, the provisions of the Agreement are "designed to ensure that the regime as a whole moves toward ever more ambitious and rigorous actions." 182

Therefore, at first reading, the integration of CBDRRC and differentiation between parties to the Paris Agreement appears to embody some ecofeminist ethics. This is because it recognises the differences between states in many different contexts and takes into account the specificities of mitigation, adaptation, finance, technology, capacity-

${ }^{178}$ FCCC, 'FCCC/AWGLCA/2008/MISC5' (n 138) Submission of Japan, 40-41, Submission of the United States, 106; FCCC, 'Ideas and Proposals on the Elements Contained in Paragraph 1 of the Bali Action Plan: Submissions from Parties. Addendum' (12 November 2008) FCCC/AWGLCA/2008/MISC.5/Add.1 Submission of Australia, 73; Daniel Bodansky, 'W[h]Ither the Kyoto Protocol? Durban and Beyond' (Harvard Project on Climate Agreements 2011) 4; Sandrine Maljean-Dubois, 'The Paris Agreement: A New Step in the Gradual Evolution of Differential Treatment in the Climate Regime?' (2016) 25 RECIEL; Meinhard Doelle, 'The Paris Agreement: Historic Breakthrough or High Stakes Experiment?' (2016) 6 Climate Law 1; Daniel Bodansky and Lavanya Rajamani, 'The Evolution and Governance Architecture of the Climate Change Regime' in Detlef Sprinz and Urs Luterbacher (eds), International Relations and Global Climate Change: New Perspectives (2nd edn, MIT Press 2016) 219.

${ }^{179}$ Paris Agreement, art 4(2).

${ }^{180}$ Paris Agreement, art 4(3).

${ }^{181}$ Bodansky and Rajamani (n 178) 234.

182 Ibid 235. 
building and transparency. ${ }^{183}$ For example, the differentiation in finance requires developed countries to provide financial resources to developing country parties and to take the lead in mobilising climate finance. ${ }^{184}$ Similarly, the Agreement creates a technology framework to "provide overarching guidance to the work of the convention's technology mechanism in promoting and facilitating enhanced action on technology development and transfer." " 185 It makes support available for collaborative approaches to research and development and facilitating access to technology. ${ }^{186}$ Finally, the introduction of INDCs and self-differentiation allows differences between states to be recognised. At the same time, the references to climate change as a "common concern" and the inclusion of transparency recognise that states are a member of a larger community which should cooperate to address shared dangers. ${ }^{187}$

Nevertheless, the extent to which this iteration of differentiation is transformative in line with ecofeminist ethics is limited. This is because the primary marker of difference in the context of climate change is "economic reality." 188 CBDRRC was originally a concept that sought to recognise the acknowledgement of industrial contributions to the global environmental crisis. ${ }^{189}$ Principle 7 of the Rio Declaration states that in the view "of the different contributions to global environmental degradation, States have common but differentiated responsibilities." ${ }^{190}$ Article 3(1) UNFCCC contains no such reference to the enhanced contributions of industrial countries to environmental degradation and placed both differentiated responsibility and respective capabilities on the same plane. ${ }^{191}$ This version of common but differentiated responsibilities indicates that the UNFCCC has weighted differentiation more towards economic capabilities and levels of economic development, rather than differing contributions to global degradation.

183 Lavanya Rajamani, 'Differentiation in a 2015 Climate Agreement' [2015] Center for Climate and Energy Solutions.

${ }^{184}$ Paris Agreement, art 9(1), 9(3).

${ }^{185}$ Bodansky et al (n 30) 241; Paris Agreement, art 10(3)-(4).

${ }^{186}$ Paris Agreement, arts 10(4)-(5).

${ }^{187}$ Paris Agreement, art 13.

${ }^{188}$ FCCC, 'FCCC/AWGLCA/2008/MISC5' (n 137).

${ }^{189}$ Lavanya Rajamani, 'The Reach and Limits of the Principle of Common but Differentiated Responsibilities and Respective Capabilities in the Climate Change Regime' in Navroz Dubash (ed), Handbook of Climate Change and India: Development, Politics and Governance (Routledge 2012) 121.

${ }^{190}$ Rio Declaration 1992, Principle 7.

${ }^{191}$ Rajamani (n 189) 121. 
Thus, the interpretation of CBDR over the evolution of the climate change has reduced its focus to economic terms rather than a more pluralised account of the historic and moral responsibility of states. The focus on "future-oriented" approaches to CBDRRC within the recent negotiations and the Paris Agreement reflects a pragmatic, problem solving approach towards mitigation that is based on the ability of states to pay. ${ }^{192}$ In this way, it emphasises the objective, disassociated and neutral logic that ecofeminists challenge for being ahistorical, and decontextualized.

Furthermore, the "future-oriented" approach to CBDRRC within the Paris Agreement also highlights a fundamental assumption and tension within the CBDRRC principle that "[e]nhanced capabilities are a direct result of industrialisation, which in turn resulted in the spike in GHG emissions that is causing climate change." 193 Some ecofeminists have warned that development through industrialisation is a colonisation through "capacity building" or technology transfer. ${ }^{194}$ Therefore, basing differentiation upon the future potential of states may "become a pretext for significant interventions to assist with climate mitigation that themselves could be geared towards the expansion of neo-liberal market-based approaches and the regulation that enables them." 195 This concern highlights that even though the CBDR principle has been incorporated within the Paris Agreement, the way in which it has been operationalised has the potential to continue the exploitation of developing countries through policies aimed at building their capacity to undertake their obligations. This approach towards differentiation is not transformational because it does not pay attention to context nor does it respect difference. Rather, it may in fact assimilate developing countries into a market as a type of economic colonisation which results in the stated intent of the law being undermined or rendered ineffective.

192 Jutta Brunnée and Charlotte Streck, 'The UNFCCC as a Negotiation Forum: Towards Common but More Differentiated Responsibilities' (2013) 13 Climate Policy 589, 592.

${ }^{193}$ Rajamani (n 189) 121.

${ }^{194}$ Vandana Shiva, 'Development as a New Project of Western Patriarchy' in Irene Diamond and Gloria Feman Orenstein (eds), Reweaving the World: The Emergence of Ecofeminism (Sierra Club Books 1990); Vandana Shiva, 'Special Report: Golden Rice and Neem: Biopatents and the Appropriation of Women's Environmental Knowledge' (2001) 29 Women's Stud Q 12.

195 Julia Dehn, 'Carbon Colonialism or Climate Justice? Interrogating the International Climate Regime from a TWAIL Perspective' (2016) 33 Windsor Yrbk Acc Jus 129, 141. 


\section{Analysing how "difference" is embedded in the UNCCD}

Unlike the UNFCCC, the UNCCD does not explicitly refer to the principle of CBDR. Instead, the Convention embeds differentiation into its overarching legal framework. ${ }^{196}$ It does this by attributing different state obligations to developed and developing countries in order to acknowledge their differences and relative asymmetries in levels of economic and technological development. At the same time, the UNCCD recognises that desertification and drought are problems of a global dimension that should be addressed at the national or local scale ${ }^{197}$ However, as will be explored below, the success of this more diffuse approach towards differentiation has hindered its operationalisation.

The implicit recognition of differences between developed and developing countries demonstrates how plurality is incorporated with the legal framework of the Convention. For example, the Convention differentiates between "general obligations" and more targeted obligations which outline additional obligations for developed country parties. ${ }^{198}$ It also recognises the geographical, cultural and social differences between different regions across the globe by incorporating four regional annexes. These may be considered an expression of differentiation because they include additional provisions that are relevant for the experiences of countries in different geographical locations that have particular economic, social, cultural and geographic conditions.

The Regional Implementation Annex for Africa outlines the purpose of the annex to "provide for the efficient and practical implementation of the Convention to address conditions specific to Africa." 199 It outlines what these conditions are and makes reference to the "difficult socio-economic conditions, exacerbated by deteriorating and fluctuating terms of trade, external indebtedness and political instability, which induce internal, regional and international migrations." 200 The other annexes to the UNCCD also refer to the broader problems that their regions face as a way to contextualise the differentiation between states and the need for plural

196 Willem Pieter Pauw et al, 'Different Perspectives on Differentiated Responsibilities in International Negotiations: A State-of-the-Art Review of the Notion of Common but Differentiated Responsibilities in International Negotiations' (Discussion Paper 6/2014, German Development Institute, 2014) 34. ${ }^{197}$ E.g. UNCCD 1994 preamble.

198 Ibid arts 4, 6.

${ }^{199}$ UNCCD 1994 Annex I (Africa) art 2(b).

${ }^{200}$ Ibid art 3(e). 
responses to drought and desertification. ${ }^{201}$ For example, the Annex for Latin America and the Caribbean directly associate the use of

"unsustainable practices ... as a result of complex interactions among physical, biological, political, social, cultural and economic factors, including international economic factors such as external indebtedness, deteriorating terms of trade and trade practices which affect markets for agricultural, fishery and forestry products"202

This sub-paragraph sets out that previous colonial and other exploitative practices by developed states has disproportionately affected the ability of Latin American and Caribbean countries to address drought and desertification. It also emphasises that factors such as deteriorating terms of trade, political and social factors all cause unsustainable development practices and are the result of these practices. Thus, this provision summarises the criticisms of development and the global market economy that maintain and reinforces difference to the detriment of some states.

Similar provisions are also found in the Regional Annex for Asia. This Annex identifies the "the significant impact of conditions in the world economy and social problems such as poverty, poor health and nutrition, lack of food security, migration, displaced persons and demographic dynamics. ${ }^{203}$ Once again, the Annex emphasises the external factors that cause and maintain differences between countries and affect the ability for states to respond to global environmental problems. Therefore, the inclusion of these annexes is transformative because it recognises difference is informed by the historical, social and political contexts of each country, which is in turn affected differently by the broader environmental problems of drought and desertification.

However, the UNCCD has had relatively limited success in operationalising the differentiated obligations. ${ }^{204}$ One reason for this is that the language of differentiation is so diffuse within the text because it has been embedded within the entire legal framework of the Convention. This means that it is harder for affected developing country parties to extract the differential language within the Convention and turn it into activities and

\footnotetext{
${ }^{201}$ UNCCD 1994 Annex II (Asia) art 2; UNCCD 1994, Annex III (Latin American and Caribbean) art 2; UNCCD 1994, Annex IV (Northern Mediterranean) art 2. 202 UNCCD 1994, Annex III (Latin American and Caribbean) art 2(b). ${ }^{203}$ UNCCD 1994 Annex II (Asia), art 2.

${ }^{204}$ Pauw et al (n 196) 35.
} 
targets to be implemented. Another reason is that the global North has traditionally seen the issue of desertification as more regional in scope and has less priority for them. ${ }^{205}$ In addition, the diffuse nature of differentiation means that it is difficult to measure progress and analyse how differentiating between different countries and/or regions has been successful (or not). Furthermore, inclusion of socioeconomic, cultural and other factors in the definition of desertification means that it is difficult to measure progress through scientific indicators, and other quantitative and qualitative measures. ${ }^{206}$ Coupled with the difficulties in determining the nature and extent of desertification, this is "among the causes of the difficult political life of the Convention." ${ }^{207}$ Nevertheless, the UNCCD offers transformative potential because it recognises that interactions between poverty, environment and natural resources can be understood at the local level, and as such should be resolved through activities at the local, national, regional and international levels. ${ }^{208}$

The above discussion has compared the integration of differentiation into the UNFCCC and the UNCCD, and evaluated the effectiveness of its operationalisation in the UNCCD. It argued that CBDR/CBDRRC has the transformative potential to recognise and respect difference between countries both in terms of their contribution to environmental degradation and their corresponding ability to address this degradation. However, the analysis of the application of differentiation between countries in the climate change regime indicates that it has been reduced to focusing on the economic ability or future economic potential of countries rather than a respecting of difference and the broader historical, political and social context of the causes and consequences of those differences. In particular, the focus of "future-oriented" determination of difference in the Paris Agreement reduces differentiation to objective, disassociated and decontextualized measurements, a far cry from ecofeminist ethics.

The treatment of differentiation in the UNCCD suggests that the negotiators attempted to develop a more transformative approach and one that is embedded in the broader historical context. The UNCCD also attempts to incorporate plurality at the local, national and international

205 Philippe Cullet, 'Differential Treatment in Environmental Law: Addressing Critiques and Conceptualizing the Next Steps' (2016) 5 TEL 305, 312.

${ }^{206}$ Zafar Adeel, Janos Bogardi and Christopher Braeuel, 'Overcoming One of the Greatest Environmental Challenges of Our Times: Re-Thinking Policies to Cope with Desertification' (United Nations University 2007) 21.

${ }^{207}$ Elisa Morgera, 'Land' in Elisa Morgera and Kati Kulovesi (eds), Research Handbook on International Law and Natural Resources (Edward Elgar 2016) 150; see also Cullet (n 205) 312.

${ }^{208}$ Adeel et al (n 206) 22. 
levels, thus enabling differentiation to be tailored depending on the specific context of different communities and locations. This was reflected in the overarching structure of the Convention, and in the incorporation of the regional annexes which pay attention to the particularities of the different regions. For these reasons, the UNCCD has integrated a more plural approach towards differentiation and CBDRRC which has the potential to be transformative. Nevertheless, the operationalisation of CBDRRC and differentiation within the UNCCD has been more circumspect and suggests that some developed country parties to the convention are unwilling to embrace its potential.

\section{CONCLUSION}

This article has compared the underlying values, assumptions and beliefs that inform the UNCCD and UNFCCC regimes through an ecofeminist analytical framework. This framework consists of three intersectional lenses which aggregate the eight boundary conditions to Karen Warren's ecofeminist ethics. To recap, these lenses were termed "inclusivity", "contextuality" and "structural pluralism". These three lenses enabled a critique of the principles, obligations and rules within the two regimes.

The comparison between UNFCCC and UNCCD through the "inclusivity" lens focused on the participation by different actors and the integration of ecosystem services. This comparison indicated that the participation by marginalised communities within the two regimes differed. In particular, the UNFCCC has been slow to support the participation by women in the climate change regime. It is only recently that the UNFCCC has incorporated gender recognition or gender mainstreaming into its policy-making process. This has been compounded by the relatively low participation by women in its negotiations. Compared to the UNFCCC, the UNCCD has been more "inclusive" since the start. As the UNCCD has been described as a "sustainable development convention", this more inclusive approach is not surprising as the principle of participation is an integral aspect to sustainable development which underpins the Convention.

However, the analysis also found that the UNFCCC has not engaged with the transformative potential of the participation by women. The analysis of the participatory provisions and the recently adopted Gender Action Program revealed that the UNFCCC has not engaged with the underlying reasons why women and other marginalised communities are disproportionately affected, what that says about human/non-human relationships understood within the regime and what this indicates about current strategies towards responding to these interconnected issues. By 
doing so, the regime has approached the participation, climate change and women nexus in a superficial way that inhibits the transformative potential of the regime.

By contrast, the UNCCD has adopted a Gender Programme of Action. This incorporates a more transformative approach towards gender. This is because it starts from a position that recognises the structural barriers faced by women, and acknowledges the fact that women are embedded within the material world. Because of this, the GPA concentrates on the local level and on developing actions that will address the barriers and exclusions faced by women there. As the GPA approaches inequalities from a social reproductive perspective, it has adopted a critical and nuanced understanding that takes into account the structural, conceptual and material barriers to participation faced by women. This indicates a greater engagement with the problems faced by women experiencing drought and desertification.

However, both regimes continue to position humanity as the central consideration for state obligations. This incorporates anthropocentric and androcentric perspectives towards non-human nature within both regimes. The introduction of neo-liberal market mechanisms, such as payment for ecosystem services, and the commodification of nature maintains the perception of humanity as separate and disembedded from nature. This means that neither regime has incorporated particularly transformational approaches towards our position as humans within an ecological community. This finding was reaffirmed by the ways in which science and technology underpin the two regimes. The analysis through the "contextual" lens found that both regimes approach science and technology as potential solutions to environmental degradation. This technological optimism is regressive and could maintain the current exploitative approach towards environmental problem solving because it reduces non-human nature to something inert and dead, thus allowing its exploitation for the pursuit of industry and capitalism.

The final lens focused on the approaches towards differentiation within the two regimes and how they integrated the principle of CBDR/CBDRRC. While the principle of CBDRRC has transformative potential to recognise and respect difference, the way in which it has been embedded within the climate change regime indicates that it has been reduced to focusing on the economic ability or future economic potential of countries rather than a respecting of differences and the broader historical, political and social context of the causes and consequences of those differences. On the other hand, the UNCCD has implicitly embedded differentiation within the structure and content of the Convention. This approach has transformative potential because of its pluralised and contextual understanding of 
difference which is also based on history. Nevertheless, the operationalisation of CBDRRC and differentiation within the UNCCD has been more circumspect and suggests that some parties to the convention are unwilling to embrace its potential.

Above all, this comparison highlights that there are some aspects of both regimes that have transformative potential. The UNCCD comes across at first reading as a regime that embodies more aspects of ecofeminist ethics, while at the same time, being still somewhat regressive. However, even though it may have the trappings of a truly transformative and successful regime, the fact that it addresses an environmental issue that has not, as yet, been recognised as a global issue (or one that affects not just developing countries), means that its potential is more circumscribed. This may be unintentional, or it may be implicitly recognising the potential of the regime, to which developed countries may be resistant.

Nevertheless, the underlying narrative of both these regimes continues to affirm an ideological perspective that disembeds humans from their surrounding ecosystem while at the same time commodifying nature to protect it. The continued commitment to neoliberal market mechanisms that maintain the denial of the body and the material reality of our reliance upon and integration within non-human nature means that, irrespective of other transformative potentials within these two regimes, each remains wedded to the ideological commitments that contribute towards environmental degradation. They also remain wedded to paradigms that marginalise and exploit those communities and bodies which are traditionally associated with nature. 